\title{
Too Persistent to Give Up: Aromaticity in Boron Clusters Survives Radical Structural Changes
}

\author{
Jordi Poater, ${ }^{\mathrm{a}, \mathrm{b}}$ Clara Viñas, ${ }^{\mathrm{c}}$ Ines Bennour, ${ }^{\mathrm{c}}$ Sílvia Escayola, ${ }^{\mathrm{d}}$ Miquel Solà*,d and \\ Francesc Teixidor*,c \\ ${ }^{a}$ Departament de Química Inorgànica i Orgànica \& Institut de Química Teòrica i Computacional \\ (IQTCUB), Universitat de Barcelona, Martí i Franquès 1-11, 08028 Barcelona, Spain \\ ${ }^{b}$ ICREA, Pg. Lluís Companys 23, 08010 Barcelona, Spain \\ ${ }^{c}$ Institut de Ciència de Materials de Barcelona, Consejo Superior de Investigaciones Científicas, Campus \\ Universitat Autònoma de Barcelona, 08193 Bellaterra, Spain Fax: (internat.) + 34-935805729 \\ ${ }^{d}$ Institut de Química Computacional i Catàlisi and Departament de Química, Universitat de Girona, C/ \\ Maria Aurèlia Capmany, 69, 17003 Girona, Catalonia, Spain
}

\begin{abstract}
$o-\mathrm{C}_{2} \mathrm{~B}_{10} \mathrm{H}_{12}$ isomerizes to $m-\mathrm{C}_{2} \mathrm{~B}_{10} \mathrm{H}_{12}$ upon heating at $400{ }^{\circ} \mathrm{C}$. Deboronation in $o-\mathrm{C}_{2} \mathrm{~B}_{10} \mathrm{H}_{12}$ is a relatively easy process, whereas it is more difficult in $m-\mathrm{C}_{2} \mathrm{~B}_{10} \mathrm{H}_{12}$. These two experimental facts indicate that $m$ $\mathrm{C}_{2} \mathrm{~B}_{10} \mathrm{H}_{12}$ is thermodynamically more stable than $o-\mathrm{C}_{2} \mathrm{~B}_{10} \mathrm{H}_{12}$. On the other hand, it is widely accepted that closo boranes and carboranes are aromatic compounds. In this work, we relate difficulty in the deboronation of the carboranes with stability and aromaticity. We do this by combining lab work and by means of DFT calculations. Computationally, our results show that the higher thermodynamic stability of $m-\mathrm{C}_{2} \mathrm{~B}_{10} \mathrm{H}_{12}$ is not related to aromaticity differences but to the location of the $\mathrm{C}$ atoms in the carborane structure. It is also demonstrated that the aromaticity observed in closo boranes and carboranes is also present in their nido counterparts and, consequently, we conclude that aromaticity in boron clusters survives radical structural changes. Further, sandwich metallocenes (e.g. ferrocene) and sandwich metallabis(dicarbollides) (e.g. $\left.\left[\mathrm{Co}\left(\mathrm{C}_{2} \mathrm{~B}_{9} \mathrm{H}_{11}\right)_{2}\right]^{-}\right)$have traditionally been considered similar. Here it is shown that they are not. Metallabis(dicarbollides) display global aromaticity whereas metallocenes present local aromaticity in the ligands. Remarkable and unique is the double probe given by ${ }^{1} \mathrm{H}$ - and ${ }^{11} \mathrm{~B}-\mathrm{NMR}$ tracing the reciprocally antipodal endocyclic open face $\mathrm{H}_{\mathrm{ec}}$ and $\mathrm{B}_{1}$. These magnetic studies have permitted to correlate both nuclei and relate them to a diatropic current in the plane at the middle of the nido $\left[\mathrm{C}_{2} \mathrm{~B}_{9} \mathrm{H}_{12}\right]^{-}$. This observation is the first and unique data that proves experimentally the existence of diatropic currents, thence aromaticity, in clusters and is comparable to the existence of diatropic currents in planar aromatic compounds. Additionally, heteroboranes with two carbon atoms have been compared to heterocycles with two nitrogen or boron atoms, $\mathrm{C}_{2} \mathrm{~B}_{10} \mathrm{H}_{12}$ carboranes against planar $\mathrm{N}_{2} \mathrm{C}_{4} \mathrm{H}_{4}$ diazines or $\left[\mathrm{B}_{2} \mathrm{C}_{4} \mathrm{H}_{4}\right]^{2-}$ diboratabenzenes, proving the higher persistence of the aromaticity of the tri-dimensional compounds in heteroatom substituted species. This research accounts very well for the "Paradigm for the Electron Requirements of Clusters" in which a closo-cluster that is aromatic upon addition of $2 \mathrm{e}^{-}$becomes also an aromatic nido species and explains the nice schemes by R.W. Rudolph and R. E. Williams.
\end{abstract}

Keywords: aromaticity; antiaromaticity; metallabis(dicarbollide); ferrocene; carborane; metallacene. 


\section{Introduction}

As time goes, metallacarboranes of the type $\left[\mathrm{M}\left(\mathrm{C}_{2} \mathrm{~B}_{9} \mathrm{H}_{11}\right)_{2}\right]^{-}(\mathrm{M}=\mathrm{Co}, \mathrm{Fe}, \mathrm{Ni})$, named as metallabis(dicarbollides), have become increasingly important. First signs of application were found in environment in nuclear waste remediation, ${ }^{1-10}$ and over the years in advanced materials, ${ }^{11-13}$ health, ${ }^{14}$ and energy. ${ }^{15-17}$ Particularly relevant is their extraordinary stability that features outer sphere electron transfer with the positive consequences this may have in molecular electronics and aspects related to energy. For any application, but very particularly for nuclear waste remediation and electron transfer related aspects, the stability of the molecule is of utmost relevance. Bench chemists have often resorted to the criterion of aromaticity to account for the high stability of certain molecules. An aromatic molecule generally possesses a higher stability and therefore exhibits lower chemical reactivity in comparison to the associated non-aromatic and antiaromatic systems.

It is known that a very large number of transition-metal sandwich or half-sandwich structures are very stable, ${ }^{18-24}$ and are described as aromatic because as a molecule they keep the ability to undergo aromatic substitution type reactions while maintaining the cyclic conjugated system. Some appealing examples of these aromatic species are ferrocene and dibenzenechromium, that easily undergo electrophilic substitution, but not electrophilic addition. In this sense, for ferrocene, $\left[\mathrm{Fe}\left(\mathrm{C}_{5} \mathrm{H}_{5}\right)_{2}\right]$, there is scientific consensus on the fact that it is an aromatic molecule, but there is controversy over whether it should be considered global ${ }^{25-26}$ or local $^{27-28}$ aromatic. Be it global or local, what is clear is that the aromaticity of these complexes requires aromaticity of the ligands. This is what happens with $\left[\mathrm{Cr}\left(\eta^{6}-\mathrm{C}_{6} \mathrm{H}_{6}\right)(\mathrm{CO})_{3}\right]$ and it is also the case for cyclobutadieneiron tricarbonyl $\left[\mathrm{Fe}(\mathrm{CO})_{3}\left(\mathrm{C}_{4} \mathrm{H}_{4}\right)\right]$, that displays electrophilic substitution and thus aromaticity as confirmed by the equal four $\mathrm{C}-\mathrm{C}$ bond lengths and the planarity of the $\mathrm{C}_{4} \mathrm{H}_{4}$ ring and ${ }^{1} \mathrm{H}$ NMR spectrum. ${ }^{29}$ The bonding in this molecule is assumed to involve the triplet state of cyclobutadiene, which is aromatic according to the Baird rule, ${ }^{30}$ interacting with two singly occupied Fe(0) orbitals. ${ }^{31}$ Remarkably, all these compounds follow the $18 \mathrm{e}^{-}$rule, that is an additional way to account for stability or lack of reactivity.

All the former complexes had planar conjugated organic ligands, able to perform electrophilic substitution and abiders of the $18 \mathrm{e}^{-}$rule. At this stage, what is the situation 
with $\left[\mathrm{M}\left(\mathrm{C}_{2} \mathrm{~B}_{9} \mathrm{H}_{11}\right)_{2}\right]^{-}(\mathrm{M}=\mathrm{Co}, \mathrm{Fe}, \mathrm{Ni})$, that do not contain planar conjugated organic ligands and have been described by computation and for the high stability of $\left[\mathrm{Co}\left(\mathrm{C}_{2} \mathrm{~B}_{9} \mathrm{H}_{11}\right)_{2}\right]^{-}$as aromatic, ${ }^{32}$ with regard to the aromaticity of their pristine ligands? Metallabis(dicarbollides) $\left[\mathrm{M}\left(\mathrm{C}_{2} \mathrm{~B}_{9} \mathrm{H}_{11}\right)_{2}\right]^{-}$are commonly mononegative $(\mathrm{M}=\mathrm{Co}, \mathrm{Fe}, \mathrm{Ni})$, but dianionic $\left[\mathrm{Fe}\left(\mathrm{C}_{2} \mathrm{~B}_{9} \mathrm{H}_{11}\right)_{2}\right]^{2-}$ and neutral $\mathrm{Ni}\left(\mathrm{C}_{2} \mathrm{~B}_{9} \mathrm{H}_{11}\right)_{2}$ are very accessible too. But all of these metallabis(dicarbollides) $\left[\mathrm{M}\left(\mathrm{C}_{2} \mathrm{~B}_{9} \mathrm{H}_{11}\right)_{2}\right]^{\mathrm{x}-}(\mathrm{M}=\mathrm{Co}, \mathrm{Fe}, \mathrm{Ni})$ have an available 18 $\mathrm{e}^{-}$count molecule: $\left[\mathrm{Fe}\left(\mathrm{C}_{2} \mathrm{~B}_{9} \mathrm{H}_{11}\right)_{2}\right]^{2-},\left[\mathrm{Co}\left(\mathrm{C}_{2} \mathrm{~B}_{9} \mathrm{H}_{11}\right)_{2}\right]^{-}$, and $\left[\mathrm{Ni}\left(\mathrm{C}_{2} \mathrm{~B}_{9} \mathrm{H}_{11}\right)_{2}\right]$.

Turning now to the issue of the aromaticity of a sandwich complex that implies that, in general, its ligands are aromatic, the consequence would be that nido $\left[\mathrm{C}_{2} \mathrm{~B}_{9} \mathrm{H}_{11}\right]^{2-}$ is aromatic too. We demonstrated ${ }^{33}$ that closo boranes $\left[\mathrm{B}_{\mathrm{n}} \mathrm{H}_{\mathrm{n}}\right]^{2-}$ abide to Wade-Mingos's rule $^{34-37}$ and that any of them, with $\mathrm{n} \geq 5$, has a polycyclic aromatic hydrocarbon equivalent with an uneven number of $\pi$ electrons pairs that obeys Hückel's rule. ${ }^{38}$ Taking this into account, what occurs with the nido $\left[\mathrm{B}_{\mathrm{n}} \mathrm{H}_{\mathrm{n}}\right]^{4-}$ series, to which nido $\left[\mathrm{C}_{2} \mathrm{~B}_{9} \mathrm{H}_{11}\right]^{2-}$ belongs? ${ }^{39}$ These have one electron pair more of electrons than closo $\left[\mathrm{B}_{n} \mathrm{H}_{n}\right]^{2-}$, and therefore if closo $\left[\mathrm{B}_{\mathrm{n}} \mathrm{H}_{\mathrm{n}}\right]^{2-}$ are aromatic it is expected that nido $\left[\mathrm{B}_{\mathrm{n}} \mathrm{H}_{\mathrm{n}}\right]^{4-}$ should be nonaromatic or antiaromatic if the parallelism between closo boranes and flat Hückel's rule abiders holds. This would be the case for typical hydrocarbon aromatic compounds. Is this what is happening with boron clusters? Or, on the contrary, the change in structure from closo to nido is a strategy at hand by the clusters to skip the aromaticity/antiaromaticity transition upon the addition of two extra electrons to keep the aromaticity? If this was the case their possibilities to maintain a stable structure would be far superior to their organic counterparts.

In this paper, we show the aromatic character of nido $\left[\mathrm{C}_{2} \mathrm{~B}_{9} \mathrm{H}_{11}\right]^{2-}$ so that it conforms to the sentence "the aromaticity of a sandwich complex implies that, in general, its ligands have to be also aromatic". We will also see that the nido $\left[\mathrm{C}_{2} \mathrm{~B}_{9} \mathrm{H}_{12}\right]^{-}$precursor of nido $\left[\mathrm{C}_{2} \mathrm{~B}_{9} \mathrm{H}_{11}\right]^{2-}$ is aromatic, too, and that the pentagonal ring $\mathrm{C}_{2} \mathrm{~B}_{3}$ in nido $\left[\mathrm{C}_{2} \mathrm{~B}_{9} \mathrm{H}_{11}\right]^{2-}$ is not more aromatic than the equivalent $\mathrm{C}_{2} \mathrm{~B}_{3}$ ring in closo $1,2-\mathrm{C}_{2} \mathrm{~B}_{10} \mathrm{H}_{12}$, despite having a conjugated open face. The $\mathrm{C}_{2} \mathrm{~B}_{3}$ ring is the one that, following the model of metallocenes, is $\eta^{5}$ coordinated to the metal in $\left[\mathrm{M}\left(\mathrm{C}_{2} \mathrm{~B}_{9} \mathrm{H}_{11}\right)_{2}\right]^{-}$. Further, we shall see that the aromatic character of a closo boron cluster depends on the number of electrons and the confined space ${ }^{40-41}$ available defined by the number of atoms in the cluster. Therefore, we shall see that any of the isomers of closo $\mathrm{C}_{2} \mathrm{~B}_{10} \mathrm{H}_{12}$ is aromatic as are closo $\left[\mathrm{B}_{12} \mathrm{H}_{12}\right]^{2-}$ 
and closo $\left[\mathrm{CB}_{11} \mathrm{H}_{12}\right]^{-}$. Moreover, we shall also see that the diatropic current in spheres, as can be interpreted the icosahedral boron clusters, is not geometrically restricted as occurs in $\mathrm{p}_{\pi}$ systems and can be present at different parallel planes. In addition, we shall observe that metallabis(dicarbollides) are not a surrogate of the metallocenes, and that their bulky and spherical ligand plays a role to their stability and possibly in their applications, besides the well documented enhanced electrochemical tuning efficiency and photoredox catalysis properties. Finally, we shall also see that boron clusters have access to a morphological detour to skip the aromaticity $\rightarrow$ antiaromaticity sequence upon the addition of $2 \mathrm{e}^{-}$.

\section{Results and Discussion}

\section{Deboronation of closo 1,7- $\mathrm{C}_{2} \mathrm{~B}_{10} \mathrm{H}_{12},\left(m-\mathrm{C}_{2} \mathrm{~B}_{10} \mathrm{H}_{12}\right)$}

The search for the relationship of aromaticity, stability, and lack of reactivity was triggered as a result of the low throughput of the deboronation of closo $m-\mathrm{C}_{2} \mathrm{~B}_{10} \mathrm{H}_{12}$ to yield nido $\left[7,9-\mathrm{C}_{2} \mathrm{~B}_{9} \mathrm{H}_{12}\right]^{-}$. It is well known the ease to remove the boron atom bound to the two carbon cluster atoms in closo $1,2-\mathrm{C}_{2} \mathrm{~B}_{10} \mathrm{H}_{12}$ also represented by $o-\mathrm{C}_{2} \mathrm{~B}_{10} \mathrm{H}_{12}$, despite that the electron count of this molecule matches the electron count of $\left[\mathrm{B}_{12} \mathrm{H}_{12}\right]^{2-}$, probably one of the most stable aromatic molecules available, following the $4 n+2$ WadeMingos' rule. ${ }^{34-37}$ There are several processes to perform the deboronation successfully. ${ }^{42-}$ ${ }^{50}$ The most typical one and perhaps the most widely used is the boiling ethanol/KOH procedure. With the aim to produce $\left[\mathrm{Co}\left(m-\mathrm{C}_{2} \mathrm{~B}_{9} \mathrm{H}_{11}\right)_{2}\right]^{-}$, we investigated the deboronation of closo $1,7-\mathrm{C}_{2} \mathrm{~B}_{10} \mathrm{H}_{12}$ (or $m-\mathrm{C}_{2} \mathrm{~B}_{10} \mathrm{H}_{12}$ ). However, what seemed to be simple became highly difficult as it was reported by Hawthorne et al. because the reaction must be carried out in an autoclave at $150^{\circ} \mathrm{C}$ for $4 \mathrm{~h}$ under autogenous pressure to lead to nido [7,9$\left.\mathrm{C}_{2} \mathrm{~B}_{9} \mathrm{H}_{12}\right]^{-}$, in our hands with very low yield. ${ }^{51}$ Other methods with other reagents have been developed that produce good yields, ${ }^{52}$ however we were interested in the boiling ethanol/KOH procedure, as $m-\mathrm{C}_{2} \mathrm{~B}_{10} \mathrm{H}_{12}$ deboronation can be directly compared with the deboronation of $o-\mathrm{C}_{2} \mathrm{~B}_{10} \mathrm{H}_{12}$. Why the two, at this stage of the research, apparently aromatic molecules $o-\mathrm{C}_{2} \mathrm{~B}_{10} \mathrm{H}_{12}$ and $m-\mathrm{C}_{2} \mathrm{~B}_{10} \mathrm{H}_{12}$ did behave so different towards the same reagent to yield so similar nido $\left[7,8-\mathrm{C}_{2} \mathrm{~B}_{9} \mathrm{H}_{12}\right]^{-}$and nido $\left[7,9-\mathrm{C}_{2} \mathrm{~B}_{9} \mathrm{H}_{12}\right]^{-}$molecules? Would not these be aromatic? Noticeable is that the same reflux temperature used for the closo $o-\mathrm{C}_{2} \mathrm{~B}_{10} \mathrm{H}_{12}$ to produce nido $\left[7,8-\mathrm{C}_{2} \mathrm{~B}_{9} \mathrm{H}_{12}\right]^{-}$leaves closo $m-\mathrm{C}_{2} \mathrm{~B}_{10} \mathrm{H}_{12}$ unchanged. For the bench chemist this would indicate that closo $m-\mathrm{C}_{2} \mathrm{~B}_{10} \mathrm{H}_{12}$ is more aromatic than closo o- 
$\mathrm{C}_{2} \mathrm{~B}_{10} \mathrm{H}_{12}$, but we shall see that this is not the case according to the computed aromaticity indicators. The immediate reaction procedure follow up would be to use higher temperature. In this case, however, an important fraction of the closo meta-cluster is degraded to boric acid esters, which in turn lead to a low yield of nido [7,9- $\left.\mathrm{C}_{2} \mathrm{~B}_{9} \mathrm{H}_{12}\right]^{-}$. Is then nido $\left[7,9-\mathrm{C}_{2} \mathrm{~B}_{9} \mathrm{H}_{12}\right]^{-}$less stable or less aromatic than nido $\left[7,8-\mathrm{C}_{2} \mathrm{~B}_{9} \mathrm{H}_{12}\right]^{-}$? Before answering these questions, we decided to optimize the synthetic procedure as the ethanol method would be very practical for the working up. To do it, we searched new parameters to improve the yield of nido $\left[7,9-\mathrm{C}_{2} \mathrm{~B}_{9} \mathrm{H}_{12}\right]^{-}$and lessen the formation of boric acid and boric acid esters during the process. As we have summarized in the experimental section and after many trials on this partial degradation by altering temperature and/or time of reaction and/or excess of base (Table 3 ), the yield of the partial degradation reaction was improved notably to $66 \%$. However, it remains poor in comparison to the yield of nido $\left[7,8-\mathrm{C}_{2} \mathrm{~B}_{9} \mathrm{H}_{12}\right]^{-}$. This anomalous behavior led us to consider that little was known and much was taken for granted with regard to the stability of the carboranes, their aromaticity, and the stability and aromaticity of their deboronated species. It took us also to revise the old but still actual, magnificent scheme shown by R.W. Rudolph on the relation between closo, nido, and arachno clusters. ${ }^{52-55}$ Therefore, we decided to carry on further research with the aim to learn about ligands that now are relevant and for sure will have an important role in the near future.

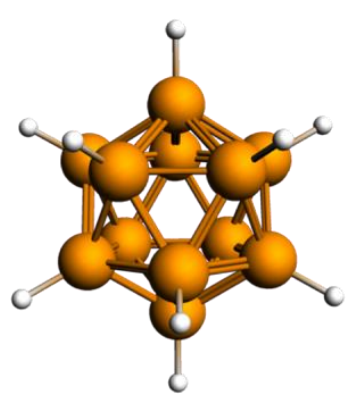

$\left[\mathrm{B}_{12} \mathrm{H}_{12}\right]^{2-}$

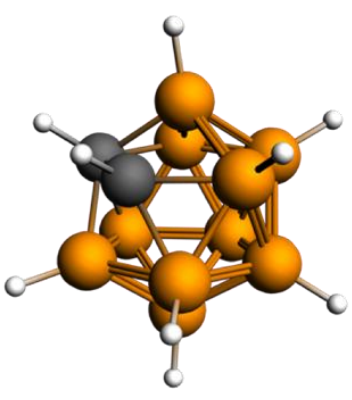

$0-\mathrm{C}_{2} \mathrm{~B}_{10} \mathrm{H}_{12}$

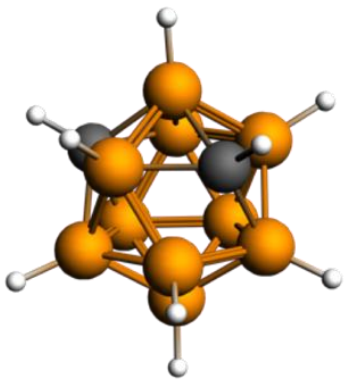

$m-\mathrm{C}_{2} \mathrm{~B}_{10} \mathrm{H}_{12}$

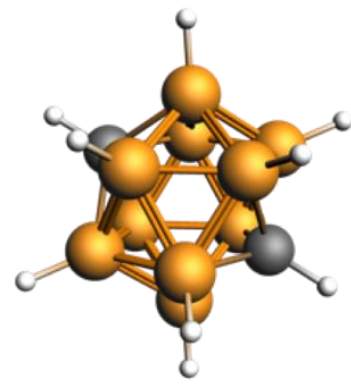

$p-\mathrm{C}_{2} \mathrm{~B}_{10} \mathrm{H}_{12}$

Figure 1. Closo ortho, meta, and para isomers of $\mathrm{C}_{2} \mathrm{~B}_{10} \mathrm{H}_{12}$, together with $\left[\mathrm{B}_{12} \mathrm{H}_{12}\right]^{2-}$.

\section{Aromaticity of closo-carboranes}

The closo $\mathrm{C}_{2} \mathrm{~B}_{10} \mathrm{H}_{12}$ parallels the aromatic closo $\left[\mathrm{B}_{12} \mathrm{H}_{12}\right]^{2-} \cdot{ }^{33}$ Both share the same number of valence electrons (50) in the same confined space. closo- $\mathrm{C}_{2} \mathrm{~B}_{10} \mathrm{H}_{12}$ has two heteroatoms that implies three isomers ortho, meta, and para (Figure 1). Further, the difference in electronegativity between the two participating elements in the cluster is $\Delta \chi(\mathrm{C}, \mathrm{B})=0.51 .^{56}$ Thus, considering the $3 \mathrm{D}$ and $2 \mathrm{D}$ relationship demonstrated earlier, ${ }^{33}$ it was sensible to 
compare these carborane isomers with planar systems with two heteroatoms, also related to a highly aromatic system, and with a $\Delta \chi$ between the participating atoms as close to $\Delta \chi(\mathrm{C}, \mathrm{B})$ as possible. In this regard, $\mathrm{C}_{6} \mathrm{H}_{6}$ and the three diazines, 1,2-, 1,3-, and 1,4diazines, commonly known as pyridazine, pyrimidine, and pyrazine, respectively, with $\Delta \chi(\mathrm{N}, \mathrm{C})=0.49,{ }^{57-58}$ and $1,2-, 1,3-$, and 1,4 -diboratabenzenes with $\Delta \chi(\mathrm{C}, \mathrm{B})=0.51^{59-61}$ would be the most adequate. It is clear for the bench chemist that both boranes and arenes, as typical aromats, are subject to substitutions restoring the aromaticity, however the diazines are also keen at additions that is contrary to strong aromaticity. In line with this, borate $^{62}$ or diboratabenzenes are subjected to chemical instability, that is also contrary to strong aromaticity. As an example, diazines upon addition they require rearomatization with oxidizing agents, which is not evidence for strong aromaticity, or when treating the 1-phenylboratabenzene anion with excess of acetic acid produces 1,4-pentadiene, cis-1,3pentadiene, and benzene. Noticeably, everything occurs with the three heterosystems, the closo $\mathrm{C}_{2} \mathrm{~B}_{10} \mathrm{H}_{12}$, the diazines, and the diboratabenzenes, for which the difference in electronegativity of the constituents is the same $\Delta \chi(X, Y) \approx 0.50$. All this is supportive of the extraordinary aromaticity of boron clusters, for both homo- or heteroboranes, whereas it is not so obvious for arenes.

These experimental evidences based on stability and reactivity are supported by theory. We will restrict our results and discussion section on the most common 12-vertex carboranes, i.e. closo $\mathrm{C}_{2} \mathrm{~B}_{10} \mathrm{H}_{12}$ and their nido derivatives, with the expectation that the results can be extended to other smaller carborane clusters, and will compare the results with the diazines and diboratabenzenes.

Table 1. Relative stabilities of closo- $\mathrm{C}_{2} \mathrm{~B}_{10} \mathrm{H}_{12}$ and their nido derivatives (kcal mol ${ }^{-1}$ ).

\begin{tabular}{lccr}
\hline & ortho & meta & para \\
\hline closo $\mathrm{C}_{2} \mathrm{~B}_{10} \mathrm{H}_{12}$ & +19.2 & +2.9 & 0.0 \\
nido $\left[\mathrm{C}_{2} \mathrm{~B}_{9} \mathrm{H}_{12}\right]^{-}$ & +16.2 & 0.0 & +26.3 \\
nido $\left[\mathrm{C}_{2} \mathrm{~B}_{9} \mathrm{H}_{11}\right]^{2-}$ & +16.6 & 0.0 & +27.5 \\
\hline
\end{tabular}

Relative Stability and aromaticity of the dicarboranes. Closo $\mathrm{C}_{2} \mathrm{~B}_{10} \mathrm{H}_{12}$ is thermally very stable but tend to isomerize to the more stable isomers (Figure 1). Upon heating at 400 
${ }^{\circ} \mathrm{C} o-\mathrm{C}_{2} \mathrm{~B}_{10} \mathrm{H}_{12}$ isomerizes to $m-\mathrm{C}_{2} \mathrm{~B}_{10} \mathrm{H}_{12}$, and near $600^{\circ} \mathrm{C} m-\mathrm{C}_{2} \mathrm{~B}_{10} \mathrm{H}_{12}$ isomerizes to $p$ $\mathrm{C}_{2} \mathrm{~B}_{10} \mathrm{H}_{12}{ }^{63}$

The preparative step from $o$ - to $m$ - is well defined and all $o$ - is converted into $m$-, and no purification is needed. The step from $m$ - to $p$ - is far more difficult as a long and troublesome purification process is needed due to the generated mixture of the two isomers. Both $m$ - and $p$-isomers are converted into each other, preventing an easy isolation. These experimental conditions indicate that a large difference in thermodynamic stability between the $o$ - and $m$ - is expected, whereas a comparable stability between the $m$ - and $p$ - isomers is likely. Indeed, this is what is computationally found, as shown in Table 1 (first row). Although these relative stabilities are for sure related to the different type of bonds $(\mathrm{C}-\mathrm{C}, \mathrm{B}-\mathrm{B}, \mathrm{C}-\mathrm{B})$ in the different isomers, they can be more easily explained considering the relative positions of both carbon atoms in the cluster. As $\chi_{\mathrm{C}}>\chi_{\mathrm{B}}, \mathrm{C}$ atoms attract higher electron density in its vicinity inducing a repulsive effect with the adjacent $\mathrm{C}$, which is the case of the ortho isomer. Whereas for the meta isomer, when one B is inserted in between the two carbon atoms, the repulsive effect is notably diminished in agreement with the Coulomb's inverse-square law. This repulsive effect is even less for the para isomer. These results are easily understood with classical physics, being the para isomer the most stable in agreement with the calculations (Table 1), but not so different with regard to the meta isomer $\left(\Delta \mathrm{E}=2.9 \mathrm{kcal} \mathrm{mol}^{-1}\right)$, a factor to be taken into account for practical applications considering the much higher price of the $p$-isomer.

The clear difference in stability between the $o$ - and $m$-isomers $(\Delta \mathrm{E}=16.3 \mathrm{kcal}$ $\mathrm{mol}^{-1}$ ), does it result in loss of aromaticity between one isomer and the other? The answer is no, if we attend to the magnetically-based nucleus independent chemical shift (NICS) values given in Table 2. If we look at Scheme 1, there are two layers enlightened, the $\mathrm{C}_{2} \mathrm{~B}_{3} / \mathrm{CB}_{4} / \mathrm{B}_{5}$ and the $\mathrm{CB}_{4} / \mathrm{B}_{5}$. This sketch is valid for closo $\left[\mathrm{B}_{12} \mathrm{H}_{12}\right]^{2-}$ and for closo o-, $m$-, and $p-\mathrm{C}_{2} \mathrm{~B}_{10} \mathrm{H}_{12}$. In closo $\left[\mathrm{B}_{12} \mathrm{H}_{12}\right]^{2-}$ each $\mathrm{B}_{5}$ ring displays a NICS of $-34.6 \mathrm{ppm}$, that indicates high aromaticity, and this value is just a little bit lower for $\mathrm{C}_{2} \mathrm{~B}_{3}$ in closo $o-\mathrm{C}_{2} \mathrm{~B}_{10} \mathrm{H}_{12}\left(-33.7 \mathrm{ppm}\right.$ ) and $-32.7 \mathrm{ppm}$ for $\mathrm{B}_{5}$ (Table 2). Interestingly, it again increases for closo $m-\mathrm{C}_{2} \mathrm{~B}_{10} \mathrm{H}_{12}$ with $-34.2 \mathrm{ppm}$ for $\mathrm{C}_{2} \mathrm{~B}_{3}$ and $-33.1 \mathrm{ppm}$ for $\mathrm{B}_{5}$ and matches the $\mathrm{B}_{5}$ values found for closo $\left[\mathrm{B}_{12} \mathrm{H}_{12}\right]^{2-}$ and that of $\mathrm{CB}_{4}$ for closo $p-\mathrm{C}_{2} \mathrm{~B}_{10} \mathrm{H}_{12}(-34.6 \mathrm{ppm})$. For a bench chemist it is clear that closo $\left[\mathrm{B}_{12} \mathrm{H}_{12}\right]^{2-}$ is by all means more stable or, in other words, less reactive than closo o- $\mathrm{C}_{2} \mathrm{~B}_{10} \mathrm{H}_{12}$, as it is also demonstrated in the following two equations: 
$\left[\mathrm{B}_{12} \mathrm{H}_{12}\right]^{2-} \rightarrow\left[\mathrm{B}_{11} \mathrm{H}_{11}\right]^{2-}+\mathrm{BH}$ compared to $o-\mathrm{C}_{2} \mathrm{~B}_{10} \mathrm{H}_{12} \rightarrow \mathrm{C}_{2} \mathrm{~B}_{9} \mathrm{H}_{11}+\mathrm{BH}$,

in which all components share the same number of electrons. At the B3LYP/6$311++\mathrm{G}(\mathrm{d}, \mathrm{p})$ level of theory, removal of a $\mathrm{BH}$ from closo $\left[\mathrm{B}_{12} \mathrm{H}_{12}\right]^{2-}$ requires $29 \mathrm{kcal}$ $\mathrm{mol}^{-1}$ more than from closo $o-\mathrm{C}_{2} \mathrm{~B}_{10} \mathrm{H}_{12}$ following this scheme. The isoelectronic and isostructural closo $\left[\mathrm{B}_{12} \mathrm{H}_{12}\right]^{2-}$ and closo o-, $m$-, and $p-\mathrm{C}_{2} \mathrm{~B}_{10} \mathrm{H}_{12}$ are a clear example that molecules having similar aromaticity may have very much distinct reactivity. ${ }^{57,64-66}$ This was demonstrated in the deboronation of closo o- and closo $m-\mathrm{C}_{2} \mathrm{~B}_{10} \mathrm{H}_{12}$ discussed in the previous section, and agrees well with the results of diazines and diboratabenzenes that can be compared with the aromaticity of $\mathrm{C}_{6} \mathrm{H}_{6}(\mathrm{NICS}(0)=-8.05 \mathrm{ppm})$ and the three diazines, 1,2-diazine $(\operatorname{NICS}(0)=-5.35), 1,3$-diazine $(\mathrm{NICS}(0)=-5.53)$ and 1,4-diazine $(\operatorname{NICS}(0)=-5.36),{ }^{67}$ and 1,2-diboratabenzene $(\operatorname{NICS}(0)=-1.92), 1,3$-diboratabenzene $(\operatorname{NICS}(0)=-2.18)$, and 1,4-diboratabenzene $(\operatorname{NICS}(0)=-1.46)$. It is informative the percentage discrepancy between the NICS(0) values of the diazine isomer and the benzene reference that are $33.5 \%$ for closo o-, $31.3 \%$ for closo $\mathrm{m}^{-}$, and $33.4 \%$ for closo $p$-, much larger than for the carboranes with respect to closo $\left[\mathrm{B}_{12} \mathrm{H}_{12}\right]^{2-}$, being $2.6 \%$ for closo $o^{-}, 1.2 \%$ for closo $m-$, and $0 \%$ for closo $p$-, but smaller than between the NICS(0) value of the diboratabenzene isomer and the benzene reference that are $76.4 \%$ for closo $o-, 72.7 \%$ for closo $m$-, and $81.4 \%$ for closo $p$-. This large percentage difference between NICS(0) for closo carboranes and diazines goes associated with only substitution reaction for the closo carboranes, whereas the diazines are subjected both to additions and substitutions, and for diazines on purpose oxidations to restore the aromaticity. When the participating elements are the same, case for closo carboranes and diboratabenzenes, the discrepancy factor has become even more severe which translates into chemical instability of the diboratabenzenes. The boratabenzene $\left[\mathrm{C}_{5} \mathrm{BH}_{6}\right]^{-}$displays a discrepancy index of $28 \%(\mathrm{NICS}(0)=-5.76)$, higher than pyridine $17.8 \% .{ }^{68}$ The discrepancies increase for the homodisubstituted species about $75 \%$ for the diboratabenzenes and $33 \%$ for the diazines. Thus, it seems that to keep the aromaticity it is better to have an electronegative element in the planar ring than an electropositive one, or alternatively an electron-rich element better than an electron-deficient element. This negative aromatic influence of B in 2D systems is not adhered to in closo 3D-carboranes. The difference is that boron in electron precise compounds (2D) tends to be a Lewis acid whereas in closo boron clusters (3D) boron compensates the shortness of electrons by high connectivity. 


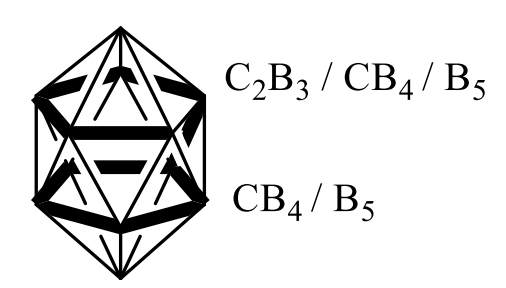

Scheme 1. Two five-membered rings in 12-vertex carboranes and $\left[\mathrm{B}_{12} \mathrm{H}_{12}\right]^{2-}$.

Table 2. NICS (in ppm) of the $\mathrm{C}_{2} \mathrm{~B}_{3}, \mathrm{CB}_{4}$, and $\mathrm{B}_{5}$ rings (measured at the centre) of closo carboranes under analysis. ${ }^{\text {a }}$

\begin{tabular}{lcc}
\hline & \multicolumn{2}{c}{ ring } \\
\cline { 2 - 3 } carborane & $\mathbf{C}_{2} \mathbf{B}_{3} / \mathbf{C B}_{\mathbf{4}}$ & $\mathbf{C B}_{\mathbf{4}} / \mathbf{B}_{\mathbf{5}}$ \\
\hline $\boldsymbol{o}-\mathbf{C}_{2} \mathbf{B}_{\mathbf{1 0}} \mathbf{H}_{12}$ & -33.7 & -32.7 \\
$\boldsymbol{o}-\left[\mathbf{C}_{2} \mathbf{B}_{9} \mathbf{H}_{12}\right]^{-}$ & -23.4 & -35.4 \\
$\boldsymbol{o}-\left[\mathbf{C}_{2} \mathbf{B}_{9} \mathbf{H}_{11}\right]^{2-}$ & -19.5 & -37.0 \\
$\boldsymbol{m}-\mathbf{C}_{2} \mathbf{B}_{10} \mathbf{H}_{12}$ & -34.2 & -33.1 \\
$\boldsymbol{m}-\left[\mathbf{C}_{2} \mathbf{B}_{9} \mathbf{H}_{12}\right]^{-}$ & -21.3 & -33.9 \\
$\boldsymbol{m}-\left[\mathbf{C}_{2} \mathbf{B}_{9} \mathbf{H}_{11}\right]^{2-}$ & -18.7 & -36.7 \\
$\boldsymbol{p}-\mathbf{C}_{2} \mathbf{B}_{10} H_{12}$ & -34.6 & -34.6 \\
$\boldsymbol{p}-\left[\mathbf{C}_{2} \mathbf{B}_{9} H_{12}\right]^{-}$ & -23.2 & -36.2 \\
$\boldsymbol{p}-\left[\mathbf{C}_{2} \mathbf{B}_{9} \mathbf{H}_{11}\right]^{2-}$ & -19.6 & -37.9 \\
\hline
\end{tabular}

${ }^{\mathrm{a}} \mathrm{NICS}$ for $\mathrm{B}_{5}$ ring in closo $\left[\mathrm{B}_{12} \mathrm{H}_{12}\right]^{2-}$ is $-34.6 \mathrm{ppm}$.

Aromaticity of the closo dicarbaboranes with regard to deboronation. It is known experimentally that closo dicarbaboranes can lead to deboronation; more easily if the two carbon atoms are adjacent, ortho, than if they are separated by a boron atom, meta, as described in the above "Deboronation of $m-\mathrm{C}_{2} \mathrm{~B}_{10} \mathrm{H}_{12}$ " section and in the Experimental Section, and even more easily than when they are separated by two carbon atoms, para, an unpractical process. nido species with the formula, nido $\left[\mathrm{C}_{2} \mathrm{~B}_{9} \mathrm{H}_{12}\right]^{-}$are produced from closo $o$ - and $m-\mathrm{C}_{2} \mathrm{~B}_{10} \mathrm{H}_{12}$ but with different positions of the two carbon atoms. The deboronation easiness of the closo dicarbaboranes shall be related to the relative stability and/or reactivity of the closo $o-, m$-, and $p-\mathrm{C}_{2} \mathrm{~B}_{10} \mathrm{H}_{12}$, and the kinetics of the involved reaction; interestingly it correlates very well with the percentage discrepancy between the $\mathrm{NICS}(0)$ value of the closo carborane isomer and the closo $\left[\mathrm{B}_{12} \mathrm{H}_{12}\right]^{2-}$ reference, although their aromatic character are very similar, as we have demonstrated earlier. The degree of deboronation difficulty of the closo carborane can also be interpreted with classical physics on the grounds of the deboronated compound, nido $\left[\mathrm{C}_{2} \mathrm{~B}_{9} \mathrm{H}_{12}\right]^{-}$. Simply one has to consider the relative stabilities of the nido $\left[\mathrm{C}_{2} \mathrm{~B}_{9} \mathrm{H}_{12}\right]^{-}$isomer clusters by which the 
electron enriched atoms prefer the edge sites, thus the positions on the pentagonal open face are preferred to the lateral sites (Figure 2). In this regard, the nido ortho and nido meta isomers should be more stable than the nido para, and between nido ortho and nido meta, the nido meta is preferred over nido ortho because of the Coulomb's law. This is what is shown in Table 1 for nido isomers $o-\left(\Delta \mathrm{E}=16.6 \mathrm{kcal} \mathrm{mol}^{-1}\right), m-(\Delta \mathrm{E}=0.0 \mathrm{kcal}$ $\left.\mathrm{mol}^{-1}\right)$, and $p-\left[\mathrm{C}_{2} \mathrm{~B}_{9} \mathrm{H}_{11}\right]^{2-}\left(\Delta \mathrm{E}=27.5 \mathrm{kcal} \mathrm{mol}^{-1}\right)$. The same argumentation is valid for the protonated species nido isomers $o-, m-$, and $p-\left[\mathrm{C}_{2} \mathrm{~B}_{9} \mathrm{H}_{12}\right]^{-}$. The higher stability of the nido $m$ - vs the nido $o-\left[\mathrm{C}_{2} \mathrm{~B}_{9} \mathrm{H}_{12}\right]^{-}$indicates that the difficulty in its formation originates in the much less reactivity of the corresponding closo species, as evidenced experimentally.

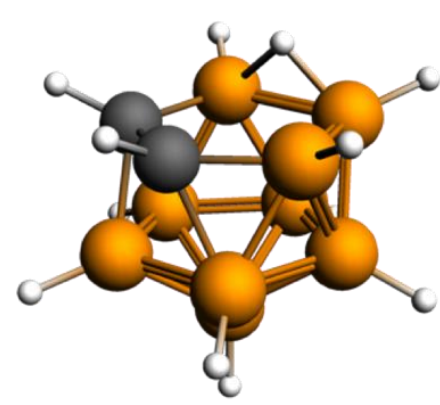

$0-\left[\mathrm{C}_{2} \mathrm{~B}_{9} \mathrm{H}_{12}\right]^{-}$

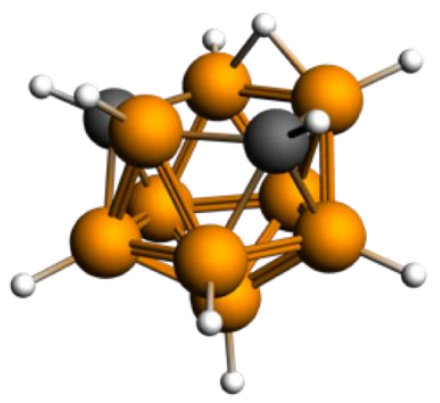

$m-\left[\mathrm{C}_{2} \mathrm{~B}_{9} \mathrm{H}_{12}\right]^{-}$

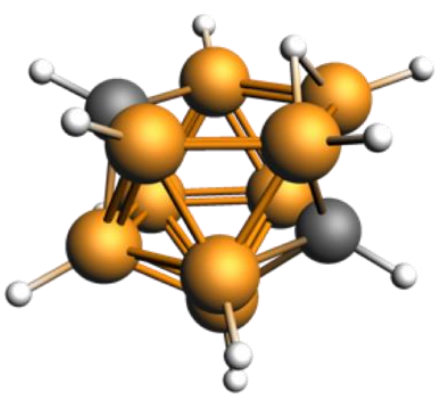

$p-\left[\mathrm{C}_{2} \mathrm{~B}_{9} \mathrm{H}_{12}\right]^{-}$

Figure 2. Nido ortho-, meta-, and para- isomers of $\left[\mathrm{C}_{2} \mathrm{~B}_{9} \mathrm{H}_{12}\right]^{-}$.

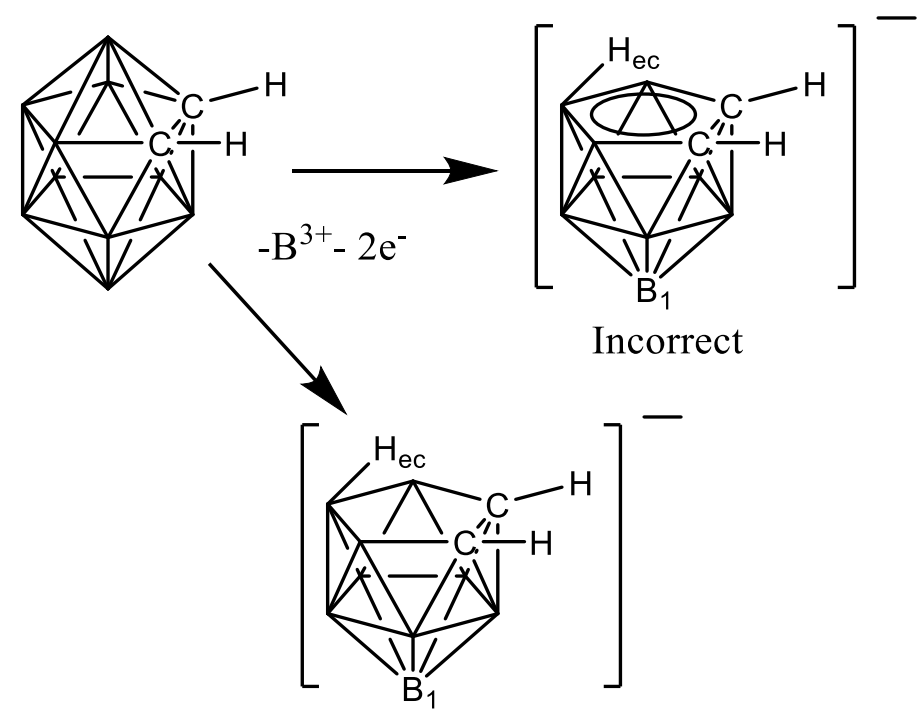

Correct

Scheme 2. Deboronation process of closo $o-\mathrm{C}_{2} \mathrm{~B}_{10} \mathrm{H}_{12}$, incorrectly showing a circle meaning aromaticity. 
Aromaticity of the nido dicarbaborane species [7,8- $\left.\mathrm{C}_{2} \mathrm{~B}_{9} \mathrm{H}_{12}\right]$ - Scheme 2 shows the deboronation process leading, in this case, to nido $\left[7,8-\mathrm{C}_{2} \mathrm{~B}_{9} \mathrm{H}_{12}\right]^{-}$. The $\mathrm{C}_{2} \mathrm{~B}_{3}$ open face reminds closely the cyclopentadiene, precursor of $\left[\mathrm{C}_{5} \mathrm{H}_{5}\right]^{-}$. We found that the on top of the face proton (endocyclic, ec) ${ }^{69}$ in $\left[7,8-\mathrm{C}_{2} \mathrm{~B}_{9} \mathrm{H}_{12}\right]^{-}$resonates near $-2.5 \mathrm{ppm}$ in the ${ }^{1} \mathrm{H}$ NMR spectrum. As this endocyclic hydrogen can be removed by a strong base it is certainly acidic, and the question that arises is how could a proton resonate at such high field? The customary answer is simple; the point is whether it was correct or not. The endocyclic proton $\left(\mathrm{H}_{\mathrm{ec}}\right)$ does resonate at high magnetic field because there is an induced ring current in the delocalized $\pi$ electrons of the aromatic $C_{2} B_{3}$ ring. Because of this interpretation, it was not uncommon to draw the ring shown in the $\mathrm{C}_{2} \mathrm{~B}_{3}$ face of the nido $\left[\mathrm{C}_{2} \mathrm{~B}_{9} \mathrm{H}_{12}\right]^{-}$representing aromaticity (see Scheme $3 \mathrm{a}$ ). However, if we think in terms of Hückel aromaticity, there is a major incongruence with this as, to have the conjugation, no $\mathrm{p}_{\pi}$ open face orbital should be part of a covalent bond, as is the $\mathrm{B}-\mathrm{H}_{e c}$. Therefore, and contrarily to what has been assumed, the $\mathrm{p}_{\pi}$ ring in the open face cannot be responsible for the upfield chemical shift of the endocyclic proton. Further, besides the anomalous chemical shift in the ${ }^{1} \mathrm{H}-\mathrm{NMR}$ of the endocyclic proton, there is also another anomalous chemical shift due to $B_{1}$ at $-37.2 \mathrm{ppm}$. This is at the highest magnetic field of the spectrum. Again, it can be interpreted to be originated in an induced ring current, but this cannot be due to the supposed delocalized system of $\pi$-electrons at the $\mathrm{C}_{2} \mathrm{~B}_{3}$ open face as it would be too far. Moreover, the anomalous chemical shifts due to the endocyclic proton and the $\mathrm{B}_{1}$ seem to be related. This indicates that their origin would be the same, supporting the proposition that is not due to the $\mathrm{C}_{2} \mathrm{~B}_{3}$ open face ring current, but to one diatropic current in an intermediate plane equidistant to both nuclei, $\mathrm{H}$ and $\mathrm{B}_{1}$. The ${ }^{1} \mathrm{H}-\mathrm{NMR}$ of the upfield endocyclic proton and the upfield ${ }^{11} \mathrm{~B}-\mathrm{NMR}$ of the $\mathrm{B}_{1}$ resonances prove the existence of diatropic currents and therefore prove the aromaticity of the nido dicarbaborane.

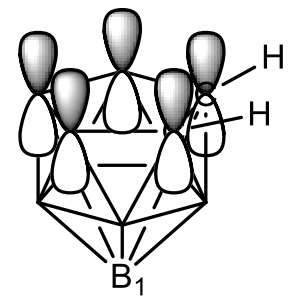

a

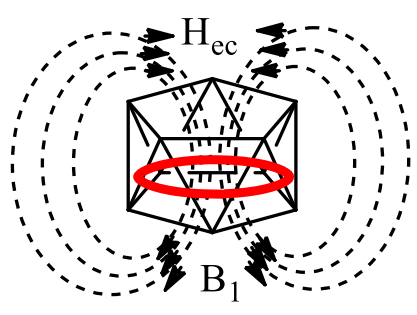

b

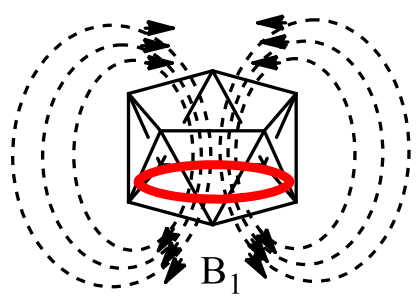

c

Scheme 3. Possible location of the ring currents in nido $\left[\mathrm{C}_{2} \mathrm{~B}_{9} \mathrm{H}_{12}\right]^{-}$and nido $\left[\mathrm{C}_{2} \mathrm{~B}_{9} \mathrm{H}_{11}\right]^{2-}$. 
This relationship between the chemical shift of the endocyclic proton and $\mathrm{B}_{1}$ can be visualized with Scheme $3 b$, which explains why $H_{\mathrm{ec}}$ and $\mathrm{B}_{1}$ are related considering that one is measured with ${ }^{1} \mathrm{H}-\mathrm{NMR}$ and the second by ${ }^{11} \mathrm{~B}-\mathrm{NMR}$. The same Scheme $3 \mathrm{~b}$ also shows a red circle suggesting a ring current placed in the centre of the pentagonal antiprism in which the centre of the icosahedron lies. This would explain the anomalous chemical shifts of the endocyclic proton and the apical $\mathrm{B}_{1}$, and their common origin (vide infra).

Is this view supported by the NICS of nido $\left[\mathrm{C}_{2} \mathrm{~B}_{9} \mathrm{H}_{12}\right]^{-}$? Largely yes. Remarkably, the $\mathrm{C}_{2} \mathrm{~B}_{3}$ layer, although being definitely aromatic according to the NICS value of -27.4 ppm, loses aromaticity with regard to the same layer in closo $1,2-\mathrm{C}_{2} \mathrm{~B}_{10} \mathrm{H}_{12}(-33.7 \mathrm{ppm})$. Conversely, the $\mathrm{B}_{5}$ layer increases aromaticity $(\mathrm{NICS}=-35.4 \mathrm{ppm})$ with regard to $\mathrm{B}_{5}$ in closo $1,2-\mathrm{C}_{2} \mathrm{~B}_{10} \mathrm{H}_{12}(-32.7 \mathrm{ppm})$. Thus, it is clear that the diatropic loop has descended from the open $\mathrm{C}_{2} \mathrm{~B}_{3}$ face to the $\mathrm{B}_{5}$ layer as it was inferred from the $\mathrm{H}_{\mathrm{ec}}$ and $\mathrm{B}_{1}$ anomalous chemical shifts (Scheme 3c).

Aromaticity of the nido $\left[\mathrm{C}_{2} \mathrm{~B}_{9} \mathrm{H}_{11}\right]^{2-}$ coordinating ligand. We have seen that the diatropic ring current in nido $\left[\mathrm{C}_{2} \mathrm{~B}_{9} \mathrm{H}_{12}\right]^{-}$has descended from the coordinating face. Does it find its continuation in nido $\left[\mathrm{C}_{2} \mathrm{~B}_{9} \mathrm{H}_{11}\right]^{2-}$ that is the real, in terms of metal sandwich formation, analogue of $\left[\mathrm{C}_{5} \mathrm{H}_{5}\right]^{-}$? The answer seems to follow the same trend (Table 2). The tendency is the same as it appears that the $\mathrm{B}_{5}$ ring is the most aromatic one. We should say unexpectedly because it is contrary to what would be common reasoning for a $\pi$ arene system to coordinate to metal by haptic covalent bonds. The "coordinating face" $\mathrm{C}_{2} \mathrm{~B}_{3} / \mathrm{CB}_{4} / \mathrm{B}_{5}$ follows the tendency to lose aromaticity manifested in the order closo $\left[\mathrm{B}_{12} \mathrm{H}_{12}\right]^{2-}>$ closo $\mathrm{C}_{2} \mathrm{~B}_{10} \mathrm{H}_{12}>$ nido $\left[\mathrm{C}_{2} \mathrm{~B}_{9} \mathrm{H}_{12}\right]^{-}>$nido $\left[\mathrm{C}_{2} \mathrm{~B}_{9} \mathrm{H}_{11}\right]^{2-}$, with NICS values for the ortho isomer of $-34.6,-33.7,-23.4$, and $-19.5 \mathrm{ppm}$, respectively. On the contrary, for the $\mathrm{B}_{5} / \mathrm{C}_{4} \mathrm{~B}$ non-coordinating ring the tendency is reversed, closo $\mathrm{C}_{2} \mathrm{~B}_{10} \mathrm{H}_{12}<$ nido $\left[\mathrm{C}_{2} \mathrm{~B}_{9} \mathrm{H}_{12}\right]^{-}<$nido $\left[\mathrm{C}_{2} \mathrm{~B}_{9} \mathrm{H}_{11}\right]^{2-}$, with NICS values of $-32.7,-35.4$, and $-37.0 \mathrm{ppm}$, respectively. To account for this situation, a similar scheme as this for nido $\left[\mathrm{C}_{2} \mathrm{~B}_{9} \mathrm{H}_{12}\right]^{-}$is suggested for nido $\left[\mathrm{C}_{2} \mathrm{~B}_{9} \mathrm{H}_{11}\right]^{2-}$ but with the aromatic ring somehow closer to $\mathrm{B}_{1}$ (Scheme $3 \mathrm{c})$. And how this should be manifested? If the density of magnetic field lines is higher on $\mathrm{B}_{1}$ in nido $\left[\mathrm{C}_{2} \mathrm{~B}_{9} \mathrm{H}_{11}\right]^{2-}$ than in nido $\left[\mathrm{C}_{2} \mathrm{~B}_{9} \mathrm{H}_{12}\right]^{-}$due to a higher aromaticity of the $\mathrm{B}_{5}$ ring, then the chemical shift of $\mathrm{B}_{1}$ in nido $\left[\mathrm{C}_{2} \mathrm{~B}_{9} \mathrm{H}_{11}\right]^{2-}$ shall be more negative than in nido $\left[\mathrm{C}_{2} \mathrm{~B}_{9} \mathrm{H}_{12}\right]^{-}$, as it is the case ( $\delta-46.1$ vs -37.2 ppm, respectively). ${ }^{70}$ 
Ring currents of closo $\left[\mathrm{B}_{12} \mathrm{H}_{12}\right]^{2-}$, closo $\mathrm{C}_{2} \mathrm{~B}_{10} \mathrm{H}_{12}$, nido $\left[\mathrm{C}_{2} \mathrm{~B}_{9} \mathrm{H}_{12}\right]^{-}$and nido $\left[\mathrm{C}_{2} \mathrm{~B}_{9} \mathrm{H}_{1}\right]^{2}$. The magnetic induced current densities of closo $\left[\mathrm{B}_{12} \mathrm{H}_{12}\right]^{2-}$, closo o $-\mathrm{C}_{2} \mathrm{~B}_{10} \mathrm{H}_{12}$, nido o$\left[\mathrm{C}_{2} \mathrm{~B}_{9} \mathrm{H}_{12}\right]^{-}$, and nido $o-\left[\mathrm{C}_{2} \mathrm{~B}_{9} \mathrm{H}_{11}\right]^{2-}$ were computationally obtained by applying an external magnetic field $\mathrm{B}_{0}$ as shown in Figure 3. The currents for the meta- and paraisomers are similar to those obtained for the ortho-species (see Supporting Information). As a reference, the Supporting Information contains the magnetic induced current densities of benzene. By convention, it is considered that the direction of the diatropic ring currents indicating aromaticity is clockwise. The magnetic induced current densities of closo $\left[\mathrm{B}_{12} \mathrm{H}_{12}\right]^{2-}$ reaches a maximum in the center of the icosahedron (see Figure 4). Interestingly, the most inner ring current in the center is paratropic. Antiaromatic molecules have paratropic inner and outer ring currents, whereas aromatic molecules present paratropic inner and diatropic outer ring currents. ${ }^{71}$ Ring currents perpendicular to the external magnetic field at the center of $\left[\mathrm{B}_{12} \mathrm{H}_{12}\right]^{2-}$ are typical of an aromatic compound. Other planes perpendicular to the external magnetic field located at 1,2, or 3 bohr above or below the central plane show also the same picture, although the intensity of the ring currents is somewhat reduced.
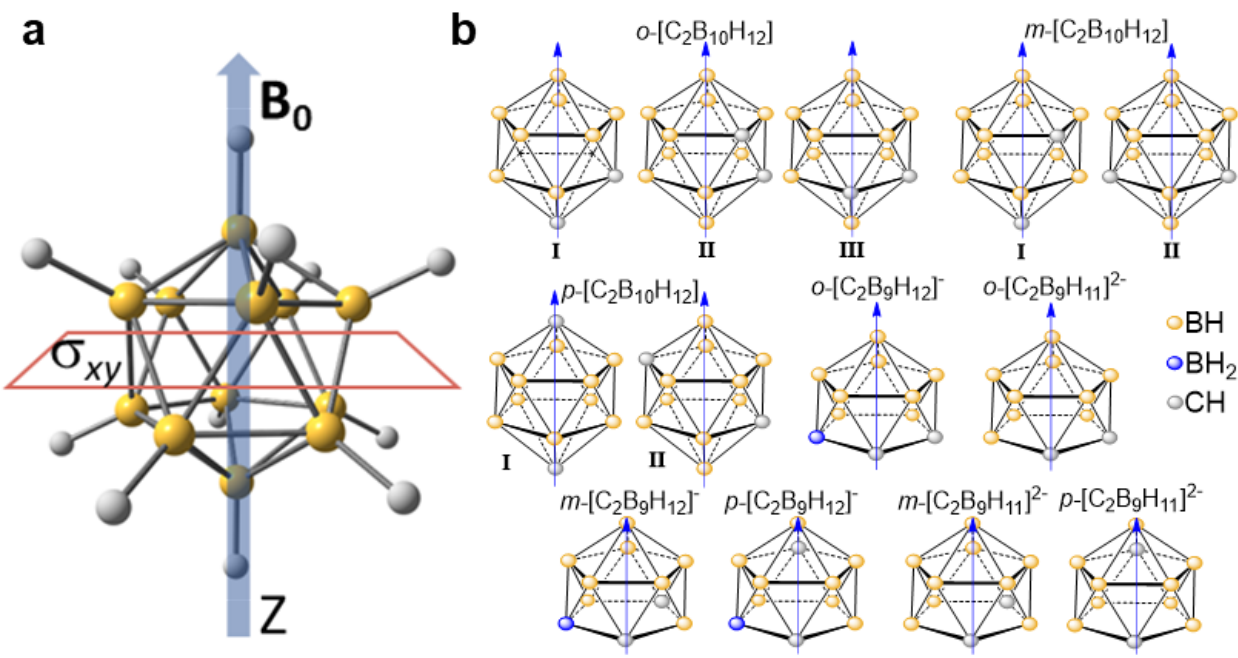

Figure 3. Representation of (a) the integration plane for the calculation of the currentdensity and the magnetic field vector $\left(\mathrm{B}_{0}\right)$ for the closo $\left[\mathrm{B}_{12} \mathrm{H}_{12}\right]^{2-}$ system. (b) Representation of the different system orientations with respect to the magnetic field vector $\mathrm{B}_{0}$ (blue arrow) for the closo o- $\mathrm{C}_{2} \mathrm{~B}_{10} \mathrm{H}_{12}$, closo $m-\mathrm{C}_{2} \mathrm{~B}_{10} \mathrm{H}_{12}$, closo $p-\mathrm{C}_{2} \mathrm{~B}_{10} \mathrm{H}_{12}$, nido o- $\left[\mathrm{C}_{2} \mathrm{~B}_{9} \mathrm{H}_{12}\right]^{-}$, nido o- $\left[\mathrm{C}_{2} \mathrm{~B}_{9} \mathrm{H}_{11}\right]^{2-}$, nido $m-\left[\mathrm{C}_{2} \mathrm{~B}_{9} \mathrm{H}_{12}\right]^{-}$, nido $p$ - $\left[\mathrm{C}_{2} \mathrm{~B}_{9} \mathrm{H}_{12}\right]^{-}$, nido $m$ $\left[\mathrm{C}_{2} \mathrm{~B}_{9} \mathrm{H}_{11}\right]^{2-}$, and nido $p-\left[\mathrm{C}_{2} \mathrm{~B}_{9} \mathrm{H}_{11}\right]^{2-}$ systems. 

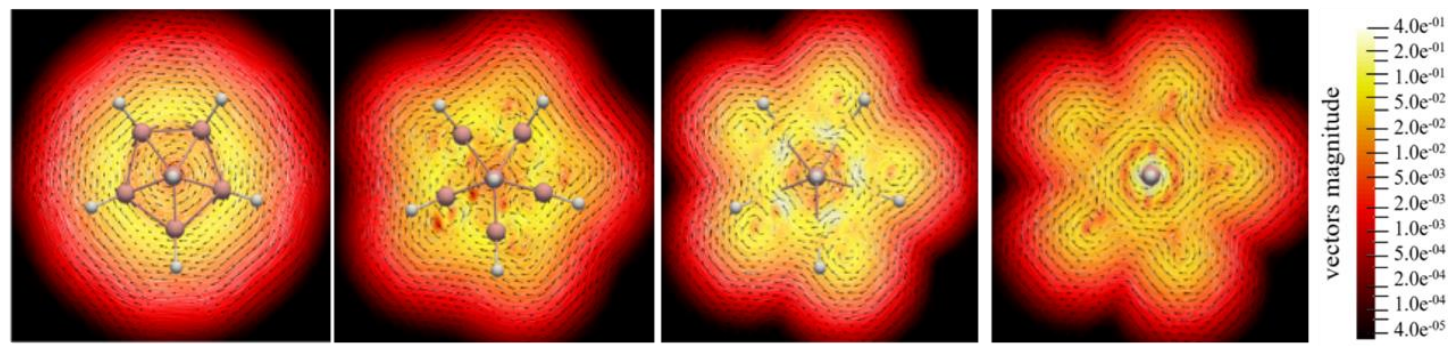

Figure 4. Representation of the current-density vector field for the closo $\left[\mathrm{B}_{12} \mathrm{H}_{12}\right]^{2-}$ system. Top view of the currents in the perpendicular plane with respect to the magnetic field vector $\mathrm{B}_{0}$ located at $0,1,2$, and 3 bohrs (from left to right, respectively) above the central plane. Units are $\mathrm{nA} \mathrm{T}^{-1}$. See Supporting Information for pictures with larger resolution.
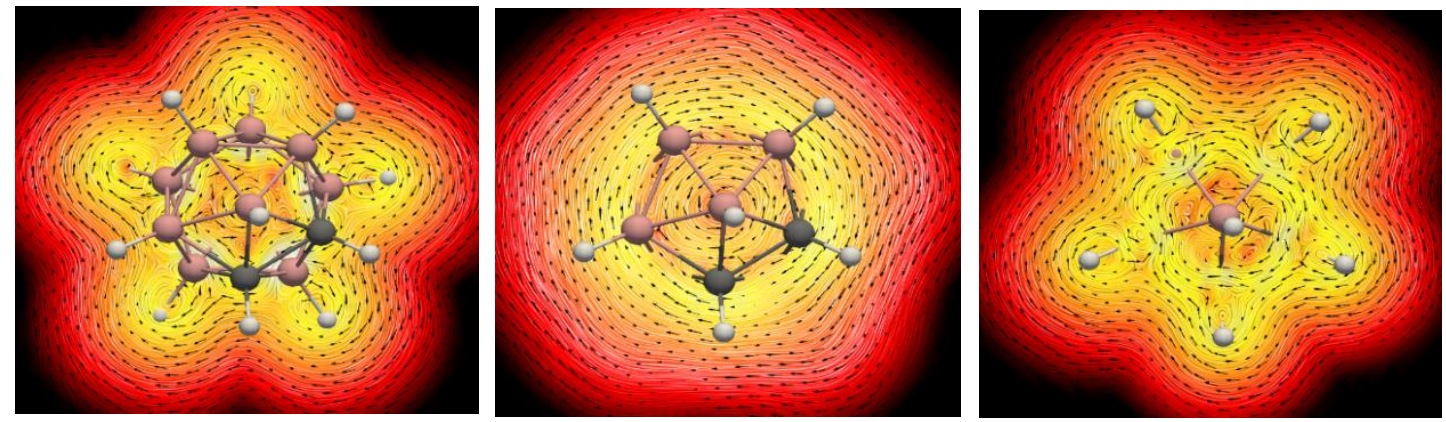

Figure 5. Representation of the current-density vector field for the closo o- $\left[\mathrm{C}_{2} \mathrm{~B}_{10} \mathrm{H}_{12}\right]$ system in orientation III (Figure 3). See Supporting Information for the rest of orientations of the external magnetic field. Top view of the currents in the $\sigma_{x y}$ plane located at $-2,0$, and 2 bohrs (from left to right, respectively) above the plane located in the middle of the two 5-membered rings (parallel to the 5-membered ring planes). Color scale given in Figure 4. Units are $\mathrm{nA} \mathrm{T}^{-1}$. See Supporting Information for pictures with larger resolution.

Figure 5 depicts the magnetic induced current densities of closo o $-\mathrm{C}_{2} \mathrm{~B}_{10} \mathrm{H}_{12}$. Change of $\mathrm{BH}^{-}$by $\mathrm{CH}$ does not produce a notable change of the observed ring currents. One can conclude that the aromaticity of the system is affected only slightly by moving from closo $\left[\mathrm{B}_{12} \mathrm{H}_{12}\right]^{2-}$ to closo $o-\mathrm{C}_{2} \mathrm{~B}_{10} \mathrm{H}_{12}$. This is not unexpected as we keep the closo aromatic structure of the borohydride. On the other hand, when we move from closo o- $\mathrm{C}_{2} \mathrm{~B}_{10} \mathrm{H}_{12}$ carborane to nido $o-\left[\mathrm{C}_{2} \mathrm{~B}_{9} \mathrm{H}_{12}\right]^{-}$, there is a clear decrease of the diatropic intensity in the central part of the polyhedron (the central plane is considered the plane in the middle of the two pentagonal rings), indicating a reduction of the aromatic character of this species (see Figure 6). Still, the picture of the ring currents indicates that we are dealing with an aromatic compound, despite it is less aromatic than the closo $\left[\mathrm{B}_{12} \mathrm{H}_{12}\right]^{2-}$ or closo o$\mathrm{C}_{2} \mathrm{~B}_{10} \mathrm{H}_{12}$. As we move from the central plane, the currents tend to be more disorganized. 
Finally, for species nido $o-\left[\mathrm{C}_{2} \mathrm{~B}_{9} \mathrm{H}_{11}\right]^{2-}$, the ring currents are similar to those obtained for nido o- $\left[\mathrm{C}_{2} \mathrm{~B}_{9} \mathrm{H}_{12}\right]^{-}$(see Figure 7).
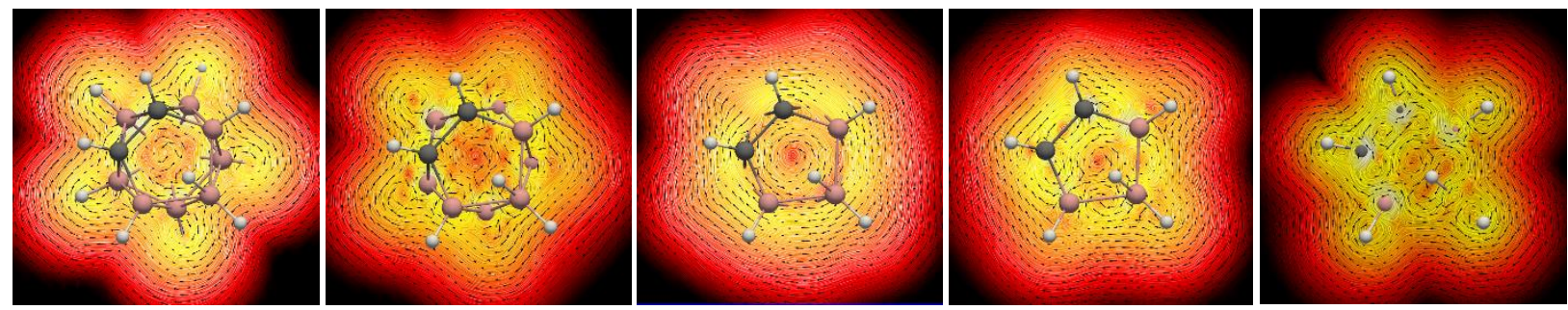

Figure 6. Representation of the current-density vector field for the nido $o-\left[\mathrm{C}_{2} \mathrm{~B}_{9} \mathrm{H}_{12}\right]^{-}$ system. Top view of the currents in the perpendicular plane with respect to the magnetic field vector $\mathrm{B}_{0}$ located at $-2,-1,0,1$, and $2 \mathrm{bohr}$ (from left to right, respectively) above the plane located in the middle of the two 5-membered rings (parallel to the 5-membered ring planes). Color scale given in Figure 4. Units are nA $\mathrm{T}^{-1}$. See Supporting Information for pictures with larger resolution.
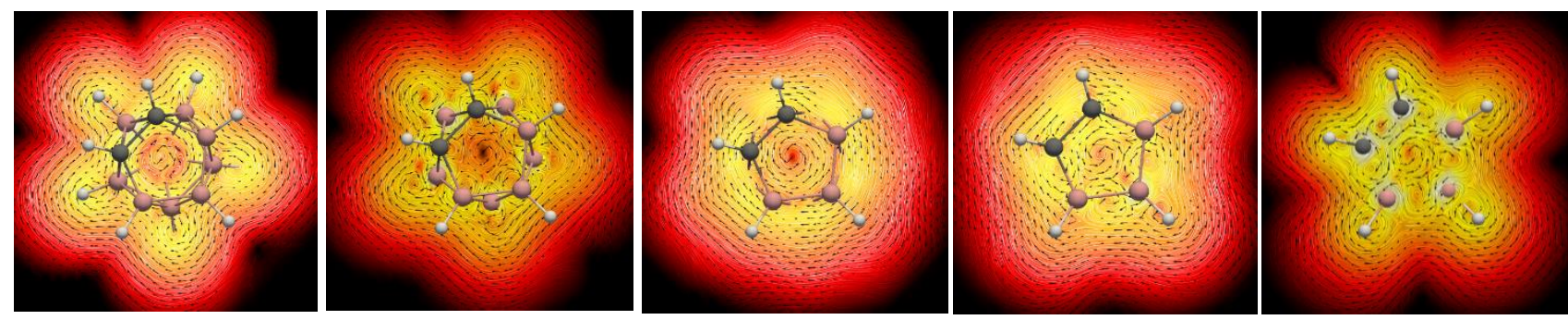

Figure 7. Representation of the current-density vector field for the nido $o-\left[\mathrm{C}_{2} \mathrm{~B}_{9} \mathrm{H}_{11}\right]^{2-}$ system. Top view of the currents in the perpendicular plane with respect to the magnetic field vector $\mathrm{B}_{0}$ located at $-2,-1,0,1$, and $2 \mathrm{bohr}$ (from left to right, respectively) above the plane located in the middle of the two 5-membered rings (parallel to the 5-membered ring planes). Color scale given in Figure 4. Units are nA $\mathrm{T}^{-1}$. See Supporting Information for pictures with larger resolution.

\section{Considerations on the aromaticity of $\left[\mathrm{Co}\left(\mathrm{C}_{2} \mathrm{~B}_{9} \mathrm{H}_{11}\right)_{2}\right]^{-}$as an example of} metallabis(dicarbollides) and their singularity versus the metallocenes. Since their discovery, metallabis(dicarbollides) $\left[\mathrm{M}\left(\mathrm{C}_{2} \mathrm{~B}_{9} \mathrm{H}_{11}\right)_{2}\right]^{-}(\mathrm{M}=\mathrm{TM})$ (Figure 8) have been considered the equivalent in boron clusters to the metallocenes, but they are not as we shall demonstrate here. They share the property of having one solid structure difficult to be reorganized, thus allowing outer electron transfer that is commonly fast. Both undergo typical aromatic substitution reactions. And both show continuous electron delocalization, at least in part of the molecule. However, inspection of both molecular structures shows a remarkable difference. The word sandwich, which is applied to both molecules, is adequate for the metallocenes because in their case two parallel planar ligands, to follow the aromatic typical concept, have a metal filling in between. However, 
the generated pentagonal pyramid does not fit in the classical concept of aromaticity as in fact, what is happening is that coordination to metal by the cyclopentadienyl ligand does not prevent that they exhibit aromatic properties, although the aromaticity of the ligands can be somewhat reduced as it was demonstrated for the benzene ring of $\left[\mathrm{Cr}\left(\eta^{6}-\right.\right.$ $\left.\left.\mathrm{C}_{6} \mathrm{H}_{6}\right)(\mathrm{CO})_{3}\right]{ }^{72}$ Thus, it would seem adequate to say that ferrocene exhibits aromatic properties rather than refer to it as an aromatic compound. This conclusion is reinforced by the work of Fowler et al. showing that the two cyclopentadienyl anions support individual diatropic ring currents. ${ }^{28}$ Conversely, the metallabis(dicarbollides) are made of two icosahedra in which the metal occupies one vertex. If we take into account the definition of aromaticity of Chen and Schleyer as "a manifestation of electron delocalization in closed circuits, either in two or three dimensions", ${ }^{68}$ the $\left[\mathrm{M}\left(\mathrm{C}_{2} \mathrm{~B}_{9} \mathrm{H}_{11}\right)_{2}\right]$ conforms to a structure, the icosahedron, that is compatible with aromaticity because it can generate a closed circuit. Therefore, metallabis(dicarbollides) are aromatic compounds, whereas metallocenes display aromatic behavior. In other words, metallabis(dicarbollides) display global aromaticity whereas metallocenes present local aromaticity in the ligands.

This can be well observed by the ring currents depicted in Figure 9 with the direction of the magnetic field shown in Figure 8. For $\left[\mathrm{Co}\left(\mathrm{C}_{2} \mathrm{~B}_{9} \mathrm{H}_{11}\right)\right]^{+}$, there is a clear external diatropic ring current from 1 to 5 bohrs with a maximum located at around the center. The intensity of the current density seems to indicate a slightly loss of aromaticity when moving from nido o- $\left[\mathrm{C}_{2} \mathrm{~B}_{9} \mathrm{H}_{11}\right]^{2-}$ to closo $\left[\mathrm{Co}\left(\mathrm{C}_{2} \mathrm{~B}_{9} \mathrm{H}_{11}\right)\right]^{+}$, although care has to be taken when using the ring currents and the NICS as indicators of aromaticity when metal atoms do participate, as paratropic currents are produced in this situation that perturb the diatropic current leading to misunderstandings. ${ }^{73}$ A similar situation is found for closo $\left[\mathrm{Co}\left(\mathrm{C}_{2} \mathrm{~B}_{9} \mathrm{H}_{11}\right)_{2}\right]^{-}$(Figure 10), but now the intensity of the current density seems to be as large as that of nido $o-\left[\mathrm{C}_{2} \mathrm{~B}_{9} \mathrm{H}_{11}\right]^{2-}$. Interestingly, the highest intensity of current density is found inside the icosahedron of the cobaltacarboranes, not far from the Co atom, whereas in ferrocene the highest intensity of current density is found outside the pentagonal pyramid and far from $\mathrm{Fe} .{ }^{28}$ We think that this result is a clear indication that we have global aromaticity in metallabis(dicarbollides) and local in ferrocenes. 

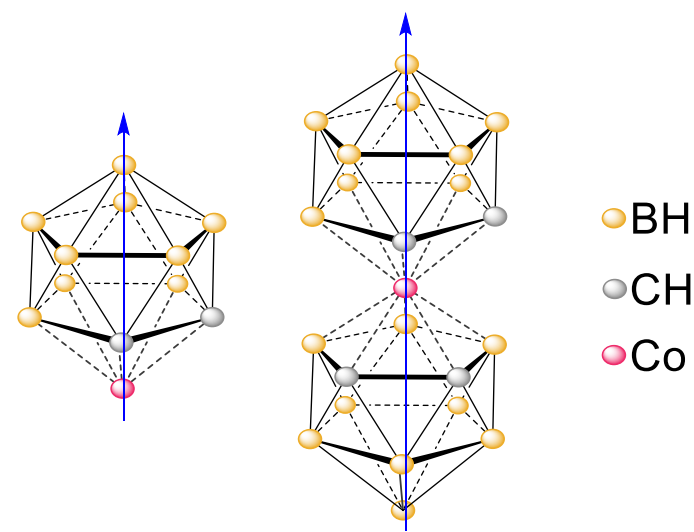

Figure 8. Representation of the orientation of the magnetic field vector, magnetic field vector $\mathrm{B}_{0}$ (blue arrow) for the closo $\left[\mathrm{Co}\left(\mathrm{C}_{2} \mathrm{~B}_{9} \mathrm{H}_{11}\right)\right]^{+}$and closo $\left[\mathrm{Co}\left(\mathrm{C}_{2} \mathrm{~B}_{9} \mathrm{H}_{11}\right)_{2}\right]^{-}$systems. 

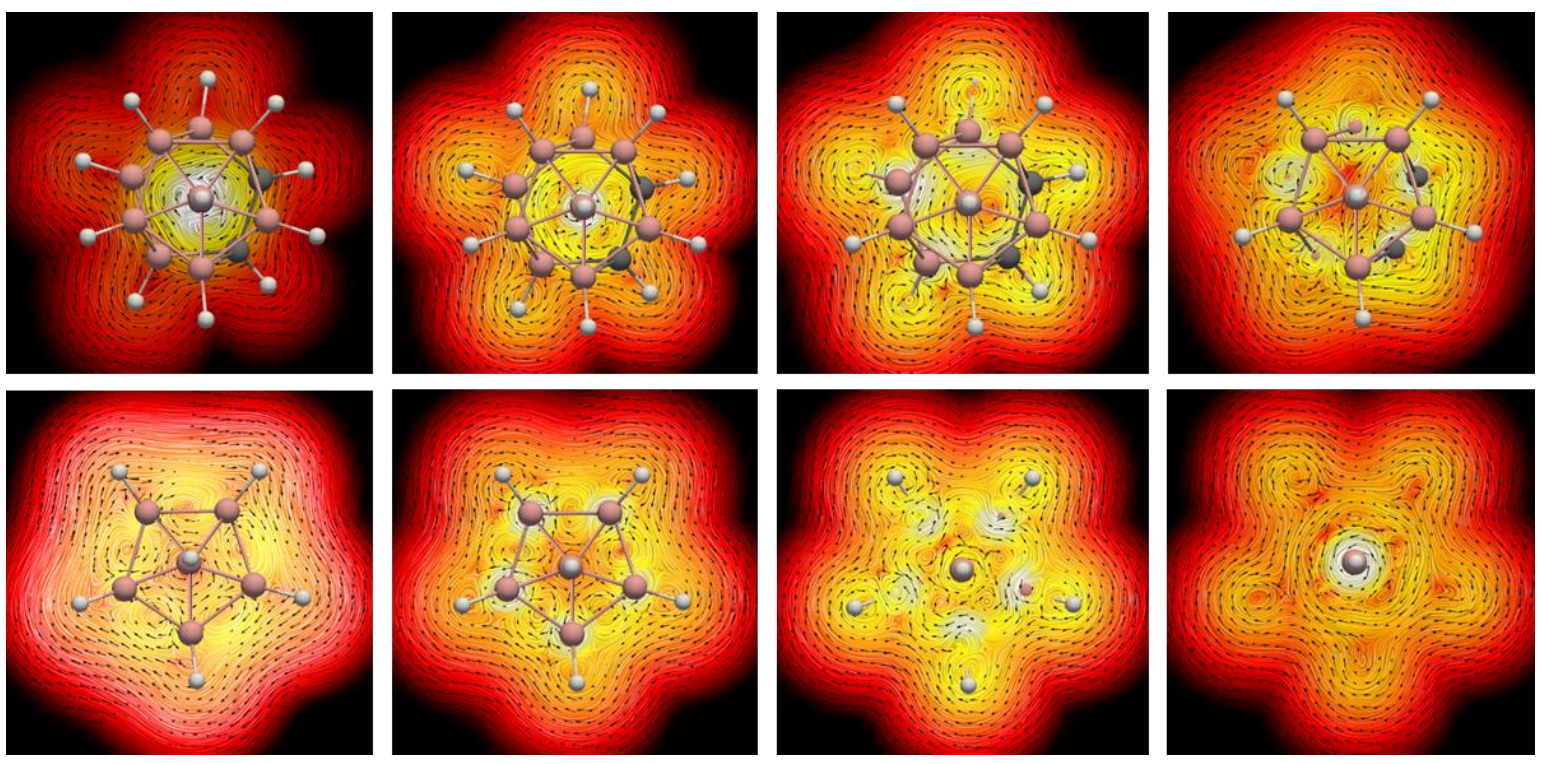

Figure 9. Representation of the current-density vector field using the LIC method for the closo $\left[\mathrm{Co}\left(\mathrm{C}_{2} \mathrm{~B}_{9} \mathrm{H}_{11}\right)\right]^{+}$system. Top view of the currents in the planes parallel to the 5membered rings located $0,1,2$, and 3 bohr (on top, and from left to right, respectively); and 4, 5, 6, and 7 bohr (on bottom, and from left to right, respectively). Being the plane at 0 bohr the one containing the Co atom, and the plane at 4 bohr the one in the middle of the two 5-membered rings Color scale given in Figure 4. Units are nA $\mathrm{T}^{-1}$. See Supporting Information for pictures with larger resolution.
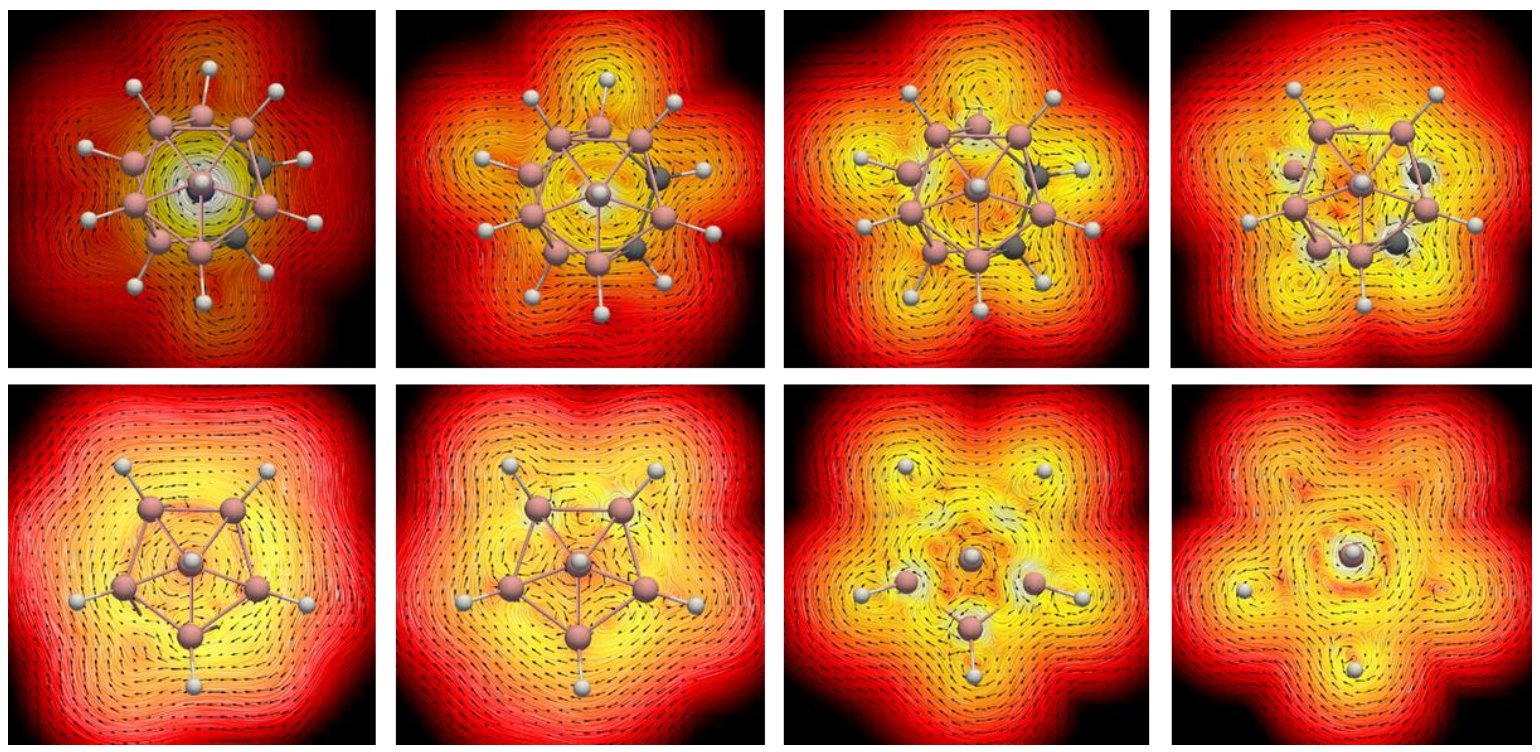

Figure 10. Representation of the current-density vector field using the LIC method for the closo $\left[\mathrm{Co}\left(\mathrm{C}_{2} \mathrm{~B}_{9} \mathrm{H}_{11}\right)_{2}\right]^{-}$system. Top view of the currents in the planes parallel to the 5membered rings located $0,1,2$, and $3 \mathrm{bohr}$ (on top, and from left to right, respectively); and 4, 5, 6, and 7 bohr (on bottom, and from left to right, respectively). Being the plane at $0 \mathrm{bohr}$ the one containing the $\mathrm{Co}$ atom, and the plane at 4 bohr the one in the middle of the two 5-membered rings. Color scale given in Figure 4. Units are nA T ${ }^{-1}$. See Supporting Information for pictures with larger resolution. 


\section{Conclusions}

There are several conclusions that can be drawn from this research; these refer to aromaticity of closo carboranes, aromaticity of nido carboranes, aromaticity of sandwich metallabis(dicarbollides), aromaticity and antiaromaticity, aromaticity and reactivity, and planar and spherical aromaticity.

The resistance to deboronation of the closo $m-\mathrm{C}_{2} \mathrm{~B}_{10} \mathrm{H}_{12}$ as compared to the easiness to remove the boron atom bound to the two carbon atoms in closo o- $\mathrm{C}_{2} \mathrm{~B}_{10} \mathrm{H}_{12}$ together with the isomerization of closo o $-\mathrm{C}_{2} \mathrm{~B}_{10} \mathrm{H}_{12}$ to closo $m-\mathrm{C}_{2} \mathrm{~B}_{10} \mathrm{H}_{12}$ upon heating agrees with the $\mathrm{B} 3 \mathrm{LYP} / 6-311++\mathrm{G}(\mathrm{d}, \mathrm{p})$ results indicating that the isomer meta is $16.3 \mathrm{kcal} \mathrm{mol}^{-1}$ more stable than the ortho. However, this difference is not related to aromaticity but to the location of the $\mathrm{C}$ atoms in the carborane structure.

It is to be noticed that the closed or partially closed structure of boranes permits to draw conclusions on aromaticity that otherwise would be difficult to observe in other morphologies. Experimentally, it is found that the endocyclic and acid proton on top of a pentagonal $\mathrm{C}_{2} \mathrm{~B}_{3}$ face resonates near $-2.5 \mathrm{ppm}$ in the ${ }^{1} \mathrm{H}-\mathrm{NMR}$ and its antipodal boron resonates at $-37.2 \mathrm{ppm}$ at the ${ }^{11} \mathrm{~B}-\mathrm{NMR}$. Both are at the highest upfield parts of their respective spectra, that prove the existence of diatropic currents in the plane at the middle of the cluster. Upon removal of the endocyclic proton, the $\mathrm{C}_{2} \mathrm{~B}_{3}$ generated plane is not the most aromatic of the possible cluster pentagonal planes according to NICS values. This situation contrasts with ferrocene in which the highest aromaticity is in the $\mathrm{Cp}^{-}$planes. Calculations at the B3LYP/6-311++G(d,p) level of theory also prove that the $\mathrm{C}_{2} \mathrm{~B}_{3}$ ring in nido carborane is not more aromatic than that in closo, despite the former represents a conjugated open face, which coordinates with the metal in metallabis(dicarbollides). More importantly, and at difference to $\mathrm{p}_{\pi}$ systems, the strongest diatropic ring currents are not found at $c a .1 \AA$ from the ring plane, but to different parallel planes between the two main five-membered rings of the cluster. This latter is responsible of the anomalous chemical shift in the ${ }^{1} \mathrm{H}-\mathrm{NMR}$ of the endocyclic proton, as well as that of $\mathrm{B}_{1}$.

For completeness, comparison to metallocenes allows to conclude that whereas metallabis(dicarbollides) are clearly aromatic, as mentioned above, metallocenes display aromatic character; alternatively, metallabis(dicarbollides) display global aromaticity whereas metallocenes present local aromaticity in the ligands. closo Boranes, e.g. $\left[\mathrm{B}_{12} \mathrm{H}_{12}\right]^{2-}$ and closo carboranes, e.g. $o-, m-, p-\mathrm{C}_{2} \mathrm{~B}_{10} \mathrm{H}_{12}$ display very similar aromaticity properties, with very large NICS negative values, about $-33 \mathrm{ppm}$, despite the existence of 
heteroatoms with $\Delta \chi(\mathrm{C}, \mathrm{B})=0.51$. This contrasts markedly with the planar diazines and diboratabenzenes also having $o-, m-, p-\mathrm{N}_{2} \mathrm{C}_{4} \mathrm{H}_{4}$ and $o-, m-, p-\left[\mathrm{C}_{4} \mathrm{~B}_{2} \mathrm{H}_{6}\right]^{2-}$ isomers that can be referenced to $\mathrm{C}_{6} \mathrm{H}_{6}$. These have similar $\Delta \chi(\mathrm{N}, \mathrm{C})=0.49$ and precise $\Delta \chi(\mathrm{C}, \mathrm{B})$ but the discrepancies with the NICS values between $\mathrm{C}_{6} \mathrm{H}_{6}$ and the diazines surpass $30 \%$, between $\mathrm{C}_{6} \mathrm{H}_{6}$ and the diboratabenzenes surpass $75 \%$, whereas between $\left[\mathrm{B}_{12} \mathrm{H}_{12}\right]^{2-}$ and closo carboranes is near $1 \%$. nido Carboranes present an aromatic character very similar to that of closo-carboranes, despite nido carboranes have lost the spherical shape of the closocarboranes or boranes. Both NICS magnetic aromaticity criteria, as well as their diatropic ring currents, support the aromatic character of nido carboranes.

Thus, it is proven the initial hypothesis that if metallabis(dicarbollides) are aromatic, their ligands must be also aromatic. Unlike aromatic hydrocarbons that become antiaromatic when two electrons are either added or removed, carboranes keep their aromaticity even when deboronated because they adapt to a different geometry. Therefore, aromaticity in boron clusters survives radical structural changes. When two electrons are added to a closo with $\mathrm{n}$ vertexes it becomes a nido with $\mathrm{n}-1$ vertexes to preserve the initial aromaticity. This possibility is not feasible to planar conjugated organic molecules with $4 n+2 \pi$ electron counting, and highlights the uniqueness of boron clusters with regard to the aromaticity. Further it accounts very well for the "Paradigm for the Electron Requirements of Clusters" by R.W. Rudolph in which a closo cluster that is aromatic upon addition of 2e- becomes a nido species (actually also aromatic according to this work), and explains the nice schemes by R.W. Rudolph and R. E. Williams.

\section{Experimental Section}

Bench work: Partial degradation or deboronation of closo 1,2- $\mathrm{C}_{2} \mathrm{~B}_{10} \mathrm{H}_{12}$ and closo 1,7$\mathrm{C}_{2} \mathrm{~B}_{10} \mathrm{H}_{12}$ has been done in a comparative way to show the differences of the apparently similar but in reality very different isomers. Despite there are alternative methods of partial degradation of closo $1,7-\mathrm{C}_{2} \mathrm{~B}_{10} \mathrm{H}_{12}$ indicated in the text, the reported autoclave method $^{51}$ with $\mathrm{KOH}$ in ethanol can be convenient for the simplicity in the working up procedure. All details of the partial degradation procedures done and the NMR characterization are extensively indicated in the S.I.

The reported general procedure is: $200 \mathrm{mg}$ (1.38 mmols) of closo 1,7- $\mathrm{C}_{2} \mathrm{~B}_{10} \mathrm{H}_{12}$ and 388 $\mathrm{mg}(6.94 \mathrm{mmols})$ of $\mathrm{KOH}$ were mixed with $5 \mathrm{ml}$ of ethanol in an autoclave to preserve the solvent at $130^{\circ} \mathrm{C}$ for $4 \mathrm{~h}$. The resulting white precipitate was filtered off and the solvent 
evaporated in vacuum to give nido $\left[7,9-\left(\mathrm{C}_{2} \mathrm{~B}_{9} \mathrm{H}_{11}\right)\right]^{2-}$. Drops of water were added followed by drops from a solution of diluted $\mathrm{HCl}$ until having a $\mathrm{pH}$ equal to 3 . The precipitation by adding $132 \mathrm{mg}(1.38 \mathrm{mmols})$ of $\left[\mathrm{HNMe}_{3}\right] \mathrm{Cl}$ gave $176 \mathrm{mg}$ of $\left[\mathrm{HNMe}_{3}\right][7,9-$ nido$\left.\left(\mathrm{C}_{2} \mathrm{~B}_{9} \mathrm{H}_{12}\right)\right](66 \%)$.

Table 3: Summary of the different parameters used for the partial degradation of the closo $m-\mathrm{C}_{2} \mathrm{~B}_{10} \mathrm{H}_{12}$ cluster

\begin{tabular}{|c|c|c|c|c|}
\hline \multicolumn{3}{|c|}{ Working conditions } & \multirow[b]{2}{*}{$\begin{array}{l}\text { Presence of the starting } \\
\text { closo } m-\mathrm{C}_{2} \mathrm{~B}_{10} \mathrm{H}_{12} \text { cluster }\end{array}$} & \multirow[b]{2}{*}{$\begin{array}{c}\text { nido meta } \\
{\left[\mathrm{HNMe}_{3}\right]\left[m-\mathrm{C}_{2} \mathrm{~B}_{9} \mathrm{H}_{12}\right]} \\
\text { Yield }(\%)\end{array}$} \\
\hline $\mathbf{T}\left({ }^{\circ} \mathbf{C}\right)$ & Time (hours) & $\mathrm{n}_{\text {eq }}$ of $\mathrm{KOH}$ & & \\
\hline 110 & \multirow{3}{*}{4} & \multirow{7}{*}{5} & \multirow{6}{*}{$\sqrt{ }$} & 38.2 \\
\hline 115 & & & & 40.8 \\
\hline 120 & & & & 45.3 \\
\hline \multirow[t]{4}{*}{130} & 1 & & & - \\
\hline & 2 & & & 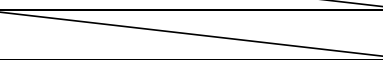 \\
\hline & 3 & & & 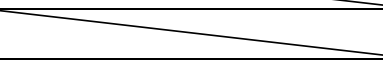 \\
\hline & 4 & & & 66.1 \\
\hline \multirow[t]{2}{*}{150} & \multirow[t]{2}{*}{4} & 3 & $\sqrt{ }$ & 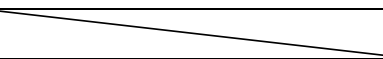 \\
\hline & & \multirow[t]{2}{*}{5} & & 47.2 \\
\hline 160 & 4 & & & 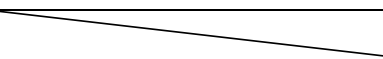 \\
\hline
\end{tabular}

Computational work: All calculations were performed with the Gaussian 09 package $^{74}$ by means of the B3LYP ${ }^{75-77}$ hybrid density functional and the $6-311++\mathrm{G}(\mathrm{d}, \mathrm{p})$ basis set. ${ }^{78}$ The geometry optimizations were carried out without symmetry constraints, and analytical Hessians were computed to characterize the optimized structures as minima (zero imaginary frequencies). Aromaticity was evaluated by means of the nucleus-independent chemical shift (NICS), ${ }^{33,40-41,68}$ proposed by Schleyer and co-workers as a magnetic descriptor of aromaticity. NICS is defined as the negative value of the absolute shielding computed at a ring center or at some other point of the system. Rings with large negative NICS values are considered aromatic. NICS values were computed using the gaugeincluding atomic orbital method (GIAO). ${ }^{79}$ The magnetic shielding tensor was calculated for ghost atoms located at the center of the rings (or polyhedra) determined by the nonweighted mean of the heavy atoms coordinates. These values are denoted as $\operatorname{NICS}(0) .{ }^{80}$ Reported ring currents were computed using the GIMIC program ${ }^{81-83}$ using the gaugeincluding atomic orbitals (GIAO) procedure with the B3LYP/6-311++G(d,p) method. ${ }^{84} \mathrm{~A}$ more detailed explanation of the GIMIC calculations is provided in the Supporting Information. 


\section{Acknowledgments}

This work has been supported by the Ministerio de Economía y Competitividad (MINECO) of Spain (Projects CTQ2017-85341-P, CTQ2016-77558-R, and MDM-2017-0767) and the Generalitat de Catalunya (projects 2017SGR39 and 2017SGR348). Excellent service by the Supercomputer center of the Consorci de Serveis Universitaris de Catalunya (CSUC) is gratefully acknowledged. 


\section{References}

1. Makrlik, E.; Vanura, P., Applications of the Dicarbollylcobaltate(III) Anion in the Water Nitrobenzene Extraction System. Talanta 1985, 32, 423-429.

2. Grimes, R. N., Metallacarboranes in the new millennium. Coord. Chem. Rev. 2000, 200, 773-811.

3. Plesek, J., Potential Applications of the Boron Cluster Compounds. Chem. Rev. 1992, 92, 269-

278.

4. Rais, J.; Selucky, P., New trends in the separation of cesium, strontitum, and transplutonides by extraction methods. Nucleon (Czechoslovakia) 1992, 1, 17-20.

5. Rais, J.; Selucky, P.; Kyrs, M., Extraction of Alkali-Metals into Nitrobenzene in Presence of Univalent Polyhedral Borate Anions. J. Inorg. Nuc. Chem. 1976, 38, 1376-1378.

6. Reilly, S. D.; Mason, C. F. V.; Smith, P. H. Cobalt(III) dicarbollide: A potential ${ }^{137} \mathrm{Cs}$ and ${ }^{90} \mathrm{Sr}$ waste extraction agent; Los Alamos National Laboratory: Los Alamos, NM, 1990.

7. Sivaev, I. B.; Bregadze, V. I., Chemistry of cobalt bis(dicarbollides). A review. Collect. Czech. Chem. Commun. 1999, 64, 783-805.

8. Viñas, C.; Gómez, S.; Bertrán, J.; Teixidor, F.; Dozol, J. F.; Rouquette, H., New polyethersubstituted metallacarboranes as extractants for ${ }^{137} \mathrm{Cs}$ and ${ }^{90} \mathrm{Sr}$ from nuclear wastes. Inorg. Chem. 1998, 37, 3640-3643.

9. Viñas, C.; Gómez, S.; Bertrán, J.; Teixidor, F.; Dozol, J. F.; Rouquette, H., Cobaltabis(dicarbollide) derivatives as extractants for europium from nuclear wastes. Chem. Comm. 1998, 191-192.

10. Gruner, B.; Plesek, J.; Baca, J.; Cisarova, I.; Dozol, J. F.; Rouquette, H.; Viñas, C.; Selucky, P.; Rais, J., Cobalt bis(dicarbollide) ions with covalently bonded CMPO groups as selective extraction agents for lanthanide and actinide cations from highly acidic nuclear waste solutions. New J. Chem. 2002, 26, 1519-1527.

11. In Boron Science: New Technologies and Applications, Hosmane, N. S., Ed. CRC Press: Boca Raton, FL, USA, 2012; pp 1-825.

12. Keener, M.; Hunt, C.; Carroll, T. G.; Kampel, V.; Dobrovetsky, R.; Hayton, T. W.; Menard, G., Redox-switchable carboranes for uranium capture and release. Nature 2020, 577, 652-655.

13. Núñez, R.; Romero, I.; Teixidor, F.; Viñas, C., Icosahedral boron clusters: a perfect tool for the enhancement of polymer features. Chem. Soc. Rev. 2016, 45, 5147-5173.

14. Boron-Based Compounds. Potential and Emerging applications in Medicine. John Wiley \& Sons Ltd: Chichester, 2018.

15. Hawthorne, M. F.; Zink, J. I.; Skelton, J. M.; Bayer, M. J.; Liu, C.; Livshits, E.; Baer, R.; Neuhauser, D., Electrical or photocontrol of the rotary motion of a metallacarborane. Science 2004, 303, 1849-1851.

16. Li, T. C.; Spokoyny, A. M.; She, C.; Farha, O. K.; Mirkin, C. A.; Marks, T. J.; Hupp, J. T., $\mathrm{Ni}(\mathrm{III}) /(\mathrm{IV}) \mathrm{Bis}$ (dicarbollide) as a Fast, Noncorrosive Redox Shuttle for Dye-Sensitized Solar Cells. J. Am. Chem. Soc. 2010, 132, 4580-4582.

17. Spokoyny, A. M.; Li, T. C.; Farha, O. K.; Machan, C. W.; She, C.; Stern, C. L.; Marks, T. J.; Hupp, J. T.; Mirkin, C. A., Electronic Tuning of Nickel-Based Bis(dicarbollide) Redox Shuttles in Dye-Sensitized Solar Cells. Angew. Chem. Int. Ed. 2010, 49, 5339-5343.

18. Aldridge, S.; Bresner, C., The coordination chemistry of boryl and borate substituted cyclopentadienyl ligands. Coord. Chem. Rev. 2003, 244, 71-92.

19. Corsini, M.; de Biani, F. F.; Zanello, P., Mononuclear metallacarboranes of groups 6-10 metals: Analogues of metallocenes - Electrochemical and X-ray structural aspects. Coord. Chem. Rev. 2006, 250, 1351-1372.

20. Deck, P. A., Perfluoroaryl-substituted cyclopentadienyl complexes of transition metals. Coord. Chem. Rev. 2006, 250, 1032-1055.

21. Nguyen, P.; Gomez-Elipe, P.; Manners, I., Organometallic polymers with transition metals in the main chain. Chem. Rev. 1999, 99, 1515-1548.

22. Siemeling, U.; Auch, T. C., 1,1'-Di(heteroatom)-functionalised ferrocenes as [N,N], [O,O] and $[\mathrm{S}, \mathrm{S}]$ chelate ligands in transition metal chemistry. Chem. Soc. Rev. 2005, 34, 584-594.

23. Williams, K. A.; Boydston, A. J.; Bielawski, C. W., Main-chain organometallic polymers: synthetic strategies, applications, and perspectives. Chem. Soc. Rev. 2007, 36, 729-744.

24. Yamaguchi, Y.; Ding, W.; Sanderson, C. T.; Borden, M. L.; Morgan, M. J.; Kutal, C., Electronic structure, spectroscopy, and photochemistry of group 8 metallocenes. Coord. Chem. Rev. 2007, 251, 515524.

25. Rausch, M. D.; Fischer, E. O.; Grubert, H., The Aromatic Reactivity of Ferrocene, Ruthenocene and Osmocene ${ }^{1,2}$. J. Am. Chem. Soc. 1960, 82, 76-82. 
26. Laskoski, M.; Steffen, W.; Smith, M. D.; Bunz, U. H. F., Is ferrocene more aromatic than benzene? Chem. Commun. 2001, 691-692.

27. Phillips, L.; Separovic, F.; Aroney, M. J., The aromaticity of ferrocene and some derivatives, ruthenocene and dibenzenechromium as determined via ring current assessment and ${ }^{13} \mathrm{C}$ anisotropic contributions to the ${ }^{1} \mathrm{H}$ NMR shielding. New J. Chem. 2003, 27, 381-386.

28. Bean, D. E.; Fowler, P. W.; Morris, M. J., Aromaticity and ring currents in ferrocene and two isomeric sandwich complexes. J. Organomet. Chem. 2011, 696, 2093-2100.

29. Seyferth, D., The rise and fall of tetraethyllead. 2. Organometallics 2003, 22, 5154-5178.

30. Baird, N. C., Quantum Organic Photochemistry. II. Resonance and Aromaticity in Lowest $3 \pi \pi^{*}$ State of Cyclic Hydrocarbons. J. Am. Chem. Soc. 1972, 94, 4941-4948.

31. Seyferth, D., (Cyclobutadiene)iron tricarbonyl - A case of theory before experiment. Organometallics 2003, 22, 2-20.

32. Junqueira, G. M. A., Remarkable aromaticity of cobalt bis(dicarbollide) derivatives: a NICS study. Theor. Chem. Acc. 2018, 137.

33. Poater, J.; Solà, M.; Vinas, C.; Teixidor, F., $\pi$-Aromaticity and Three-Dimensional Aromaticity: Two sides of the Same Coin? Angew. Chem. Int. Ed. 2014, 53, 12191-12195.

34. Mingos, D. M. P., General Theory for Cluster and Ring Compounds of Main Group and Transition-Elements. Nat. Phys. Sci. 1972, 236, 99-102.

35. Mingos, D. M. P., Polyhedral Skeletal Electron Pair Approach. Acc. Chem. Res. 1984, 17, 311319.

36. Wade, K., Structural Significance of Number of Skeletal Bonding Electron-Pairs in Carboranes, Higher Boranes and Borane Anions, and Various Transition-Metal Carbonyl Cluster Compounds. J. Chem. Soc. D Chem. Comm. 1971, 792-793.

37. Wade, K., Electron-deficient Compounds. Nelson and Sons, Ltd.: London, 1971.

38. Hückel, E., Main feature of the theory of unsaturated and aromatic compounds. Z. Elektrochemie 1937, 43, 752-788.

39. McKay, D.; Macgregor, S. A.; Welch, A. J., Isomerisation of nido- $\left[\mathrm{C}_{2} \mathrm{~B}_{10} \mathrm{H}_{12}\right]^{2-}$ dianions: unprecedented rearrangements and new structural motifs in carborane cluster chemistry. Chem. Sci. 2015, 6, 3117-3128.

40. Poater, J.; Solà, M.; Vinas, C.; Teixidor, F., A Simple Link between Hydrocarbon and Borohydride Chemistries. Chem. Eur. J. 2013, 19, 4169-4175.

41. Poater, J.; Solà, M.; Vinas, C.; Teixidor, F., Hückel's Rule of Aromaticity Categorizes Aromatic closo Boron Hydride Clusters. Chem. Eur. J. 2016, 22, 7437-7443.

42. Davidson, M. G.; Fox, M. A.; Hibbert, T. G.; Howard, J. A. K.; Mackinnon, A.; Neretin, I. S.; Wade, K., Deboronation of ortho-carborane by an iminophosphorane: crystal structures of the novel carborane adduct nido- $\mathrm{C}_{2} \mathrm{~B}_{10} \mathrm{H}_{12} \cdots \mathrm{HNP}\left(\mathrm{NMe}_{2}\right)_{3}$ and the borenium salt $\left[\left(\mathrm{Me}_{2} \mathrm{~N}\right)_{3} \mathrm{PNHBNP}\left(\mathrm{NMe}_{2}\right)_{3}\right]_{2} \mathrm{O}^{2+}\left(\mathrm{C}_{2} \mathrm{~B}_{9} \mathrm{H}_{12}\right)^{2}$. Chem. Comm. 1999, 1649-1650.

43. Fox, M. A.; Gill, W. R.; Herbertson, P. L.; MacBride, J. A. H.; Wade, K.; Colquhoun, H. M., Deboronation of C-substituted ortho- and meta-closo-carboranes using "wet" fluoride ion solutions. Polyhedron 1996, 15, 565-571.

44. Fox, M. A.; MacBride, J. A. H.; Wade, K., Fluoride-ion deboronation of p-fluorophenyl-orthoand -meta-carboranes. NMR evidence for the new fluoroborate, $\mathrm{HOBHF}_{2}^{-}$. Polyhedron 1997, 16, $2499-$ 2507.

45. Fox, M. A.; Wade, K., Cage-fluorination during deboronation of meta-carboranes. Polyhedron 1997, 16, 2517-2525.

46. Taoda, Y.; Sawabe, T.; Endo, Y.; Yamaguchi, K.; Fujii, S.; Kagechika, H., Identification of an intermediate in the deboronation of ortho-carborane: an adduct of ortho-carborane with two nucleophiles on one boron atom. Chem. Comm. 2008, 2049-2051.

47. Wiesboeck, R. A.; Hawthorne, M. F., Dicarbaundecaborane(13) and Derivatives. J. Am. Chem. Soc. 1964, 86, 1642-1643.

48. Yoo, Y.; Hwang, J. W.; Do, Y., Facile and mild deboronation of o-carboranes using cesium fluoride. Inorg. Chem. 2001, 40, 568-570.

49. Zakharki, L. I.; Kalinin, V. N., On Reaction of Amines with Barenes. Tetrahedron Lett. $1965,407$.

50. Zakharkin, L. I.; Kirillova, V. S., Cleavage of Ortho-Carboranes to (3)-1,2-Dicarbaundecarborates by Amines. Bull. Acad. Sci. USSR, Div. Chem. Sci. 1975, 24, 2484-2486.

51. Hawthorne, M. F.; Young, D. C.; Garrett, P. M.; Owen, D. A.; Schwerin, S. G.; Tebbe, F. N.; Wegner, P. A., Preparation and Characterization of (3)-1,2- and (3)-1,7Dicarbadodecahydroundecaborate(-1) Ions. J. Am. Chem. Soc. 1968, 90, 862-868.

52. Fox, M. A.; Goeta, A. E.; Hughes, A. K.; Johnson, A. L., Crystal and molecular structures of the nido-carborane anions, 7,9- and 2,9- $\mathrm{C}_{2} \mathrm{~B}_{9} \mathrm{H}_{12}$. J. Chem. Soc., Dalton Trans. 2002, 2132-2141. 
53. Rudolph, R. W., Boranes and Heteroboranes - Paradigm for Electron Requirements of Clusters. Acc. Chem. Res. 1976, 9, 446-452.

54. Wade, K., Key to Cluster Shapes. Chem. Brit. 1975, 11, 177-183.

55. Williams, R. E.; Bender, M. L., Substituent Effects on Chymotrypsin-Catalyzed Hydrolysis of Specific Ester Substrates. Can. J. Biochem. 1971, 49, 210-217.

56. Pauling, L., The Nature of the Chemical Bond. 3rd edition. Cornell University Press: Ithaca, NY, 1960.

57. El-Hamdi, M.; Tiznado, W.; Poater, J.; Solà, M., An Analysis of the Isomerization Energies of 1,2-/1,3-Diazacyclobutadiene, Pyrazole/Imidazole, and Pyridazine/Pyrimidine with the Turn-UpsideDown Approach. J. Org. Chem. 2011, 76, 8913-8921.

58. Wang, Y.; Wu, J. I. C.; Li, Q.; Schleyer, P. v. R., Aromaticity and Relative Stabilities of Azines. Org. Lett. 2010, 12, 4824-4827.

59. Herberich, G. E.; Hessner, B.; Hostalek, M., A 1,2-Diboratabenzene: Lithium Salt and Transition Metal Complexes. Angew. Chem. Int. Ed. 1986, 25, 642-643.

60. Balzereit, C.; Winkler, H.-J.; Massa, W.; Berndt, A., A 1,3-Diboratabenzene. Angew. Chem. Int. Ed. 1994, 33, 2306-2308.

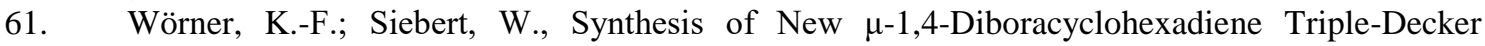
Complexes. Z. Naturforsch. B 2014, 44, 1211-1213.

62. Ashe, A. J.; Shu, P., The 1-Phenylborabenzene Anion. J. Am. Chem. Soc. 1971, 93, 1804-1805.

63. Grimes, R. N., Carboranes, 3rd Edition. In Carboranes, 3rd Edition, 2016; pp 1-1041.

64. Hoffmann, R., Perspective The Many Guises of Aromaticity. Am. Sci. 2015, 103, 18-22.

65. Matito, E.; Poater, J.; Solà, M.; Schleyer, P. v. R., Aromaticity and Chemical Reactivity. In Chemical Reactivity Theory, Chattaraj, P. K., Ed. Taylor and Francis/CRC Press: Boca Ratón, FL, USA, 2009.

66. Solà, M., Why Aromaticity Is a Suspicious Concept? Why? Front. Chem. 2017, 5, 22.

67. Feixas, F.; Matito, E.; Poater, J.; Solà, M., On the performance of some aromaticity indices: A critical assessment using a test set. J. Comput. Chem. 2008, 29, 1543-1554.

68. Chen, Z. F.; Wannere, C. S.; Corminboeuf, C.; Puchta, R.; Schleyer, P. V., Nucleus-independent chemical shifts (NICS) as an aromaticity criterion. Chem. Rev. 2005, 105, 3842-3888.

69. Buchanan, J.; Hamilton, E. J. M.; Reed, D.; Welch, A. J., The structure of $\left[7,8-\mathrm{C}_{2} \mathrm{~B}_{9} \mathrm{H}_{12}\right]^{-}$; correction of a popular misconception. Journal of the Chemical Society, Dalton Transactions 1990, 677680 .

70. Barberà, G.; Viñas, C.; Teixidor, F.; Rosair, G. M.; Welch, A. J., Synthesis and characterisation of the exo-nido molybdacarborane complex $\mathrm{Mo}\left(\eta-\mathrm{C}_{3} \mathrm{H}_{5}\right)(\mathrm{CO})_{2}\left(7,8-\mu-\mathrm{SCH}_{2} \mathrm{CH}_{2} \mathrm{~S}-7,8-\right.$ nido- $\left.\mathrm{C}_{2} \mathrm{~B}_{9} \mathrm{H}_{10}\right)$. Strong B-H-Mo 3-centre bonding. J. Organometal. Chem. 2002, 663, 221-226.

71. Fliegl, H.; Sundholm, D.; Taubert, S.; Jusélius, J.; Klopper, W., Magnetically Induced Current Densities in Aromatic, Antiaromatic, Homoaromatic, and Nonaromatic Hydrocarbons. J. Phys. Chem. A 2009, 113, 8668-8676.

72. Feixas, F.; Jiménez-Halla, J. O. C.; Matito, E.; Poater, J.; Solà, M., Is the Aromaticity of the Benzene Ring in the $\left(\eta^{6}-\mathrm{C}_{6} \mathrm{H}_{6}\right) \mathrm{Cr}(\mathrm{CO})_{3}$ complex Larger than that of the Isolated Benzene Molecule? Polish J. Chem. 2007, 81, 783-797.

73. Foroutan-Nejad, C., Is NICS a reliable aromaticity index for transition metal clusters? Theor. Chem. Acc. 2015, 134.

74. Frisch, M. J.; Trucks, G. W.; Schlegel, H. B.; Scuseria, G. E.; Robb, M. A.; Cheeseman, J. R.; Scalmani, G.; Barone, V.; Mennucci, B.; Petersson, G. A.; Nakatsuji, H.; Caricato, M.; Li, X.; Hratchian, H. P.; Izmaylov, A. F.; Bloino, J.; Zheng, G.; Sonnenberg, J. L.; Hada, M.; Ehara, M.; Toyota, K.; Fukuda, R.; Hasegawa, J.; Ishida, M.; Nakajima, T.; Honda, Y.; Kitao, O.; Nakai, H.; Vreven, T.; Jr., J. A. M.; Peralta, J. E.; Ogliaro, F.; Bearpark, M.; Heyd, J. J.; Brothers, E.; Kudin, K. N.; Staroverov, V. N.; Kobayashi, R.; Normand, J.; Raghavachari, K.; Rendell, A.; Burant, J. C.; Iyengar, S. S.; Tomasi, J.; Cossi, M.; Rega, N.; Millam, J. M.; Klene, M.; Knox, J. E.; Cross, J. B.; Bakken, V.; Adamo, C.; Jaramillo, J.; Gomperts, R.; Stratmann, R. E.; Yazyev, O.; Austin, A. J.; Cammi, R.; Pomelli, C.; Ochterski, J. W.; Martin, R. L.; Morokuma, K.; Zakrzewski, V. G.; Voth, G. A.; Salvador, P.; Dannenberg, J. J.; Dapprich, S.; Daniels, A. D.; Farkas, Ö.; Foresman, J. B.; Ortiz, J. V.; Cioslowski, J.; Fox, D. J. Gaussian 09, Gaussian, Inc.: Pittsburgh, PA, 2009.

75. Becke, A. D., Density-Functional Thermochemistry. III. The Role of Exact Exchange. J. Chem. Phys. 1993, 98, 5648-5652.

76. Lee, C. T.; Yang, W. T.; Parr, R. G., Development of the Colle-Salvetti Correlation-Energy Formula into a Functional of the Electron-Density. Phys. Rev. B 1988, 37, 785-789. 
77. Stephens, P. J.; Devlin, F. J.; Chabalowski, C. F.; Frisch, M. J., Ab-Initio Calculation of Vibrational Absorption and Circular-Dichroism Spectra Using Density-Functional Force-Fields. J. Phys. Chem. 1994, 98, 11623-11627.

78. Frisch, M. J.; Pople, J. A.; Binkley, J. S., Self-Consistent Molecular-Orbital Methods .25. Supplementary Functions for Gaussian-Basis Sets. J. Chem. Phys. 1984, 80, 3265-3269.

79. Wolinski, K.; Hinton, J. F.; Pulay, P., Efficient Implementation of the Gauge-Independent Atomic Orbital Method for NMR Chemical-Shift Calculations. J. Am. Chem. Soc. 1990, 112, 8251-8260.

80. Corminboeuf, C.; Heine, T.; Seifert, G.; Schleyer, P. V.; Weber, J., Induced magnetic fields in aromatic [n]-annulenes - interpretation of NICS tensor components. Phys. Chem. Chem. Phys. 2004, 6, 273276.

81. Fliegl, H.; Taubert, S.; Lehtonen, O.; Sundholm, D., The Gauge Including Magnetically Induced Current Method. Phys. Chem. Chem. Phys. 2011, 13, 20500-20518.

82. Jusélius, J.; Sundholm, D.; Gauss, J., Calculation of current densities using gauge-including atomic orbitals. J. Chem. Phys. 2004, 121, 3952-3963.

83. Sundholm, D.; Fliegl, H.; Berger, R. J., Calculations of Magnetically Induced Current Densities: Theory and Applications. WIREs Comput. Mol. Sci. 2016, 6, 639-678.

84. Gauss, J.; Stanton, J. F., Electron-correlated approaches for the calculation of NMR chemical shifts. In Advances in Chemical Physics, Prigogine, I.; Rice, S. A., Eds. 2002; Vol. 123, pp 355-422. 
Graphic for the TOC

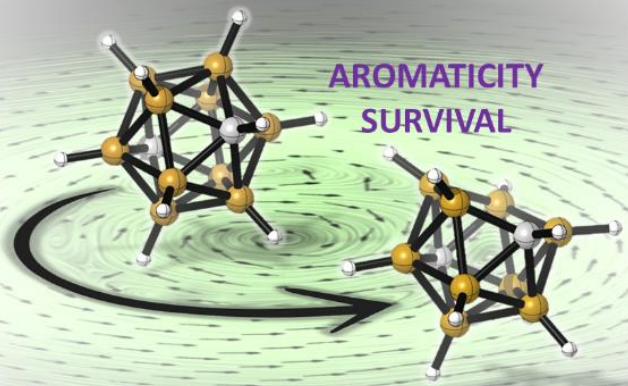

